\title{
The effect of dwell on thermomechanical fatigue in superaustenitic steel Sanicro 25
}

\author{
Roman Petras ${ }^{1}$, Ivo Šulák ${ }^{1}$, and Jaroslav Polak ${ }^{1}$ \\ ${ }^{1}$ Institute of Physics of Materials Czech Academy of Sciences
}

August 3, 2020

\begin{abstract}
Superaustenitic steel Sanicro 25 has been subjected to in-phase and out-of-phase thermomechanical fatigue cycles in the temperature range from $250^{\circ} \mathrm{C}$ to $700^{\circ} \mathrm{C}$. Both constant strain rate cycling and cycling with 10 minutes dwell at peak temperature were applied. The effect of the dwells on the cyclic response, internal structure and damage mechanism was studied. Cyclic hardening/softening curves, cyclic stress-strain curves and fatigue life curves were evaluated. The transmission electron microscopy was used to find modifications of the internal structure and precipitation of the nanoparticles. 10 min dwell at maximum temperature modified substantially the dislocation arrangement. Various nanoparticles representing the obstacles for dislocation motion were analysed and identified by energy dispersive X-ray spectroscopy in scanning transmission electron microscope. The damage mechanism operating under specific loading conditions was investigated on the surface as well as in the interior of the cycled specimens. Scanning electron microscopy combined with focused ion beam and electron backscatter diffraction was adopted to reveal the respective mechanisms responsible for crack nucleation and propagation. Effect of dwells on fatigue behaviour, modification of internal structure and damage mechanisms are analysed and discussed.
\end{abstract}

\section{Introduction}

The production of energy with the lowest impact on the environment has become of topical concern. Even though the participation of electricity generation such as renewable energy resources increases, the power plants do still represent a dominant contribution regarding electricity production all over the world. A new generation of thermal power plants, Advanced ultra-supercritical (A-USC) power plants working at temperatures up to $700{ }^{\circ} \mathrm{C}$ have been designed to assure enhanced efficiency and to achieve the reduction of emissions as well. The materials utilized in boiler construction have to be chosen according to both service and economy criteria. To minimalize the expenses concerning superheat and reheat tubing, highly alloyed advanced austenitic stainless steels such as NF709, H3RC and Sanicro 25 should be used ${ }^{1}$. Sanicro 25 exhibits very good resistance to steam oxidation, high temperature corrosion and has high creep rupture strength, higher than the other austenitic stainless steels available today ${ }^{2,3}$.

The original interest was devoted to the creep resistance ${ }^{2,4-7}$ Basic study of the low cycle fatigue at ambient and high temperature of Sanicro $25^{8}$ and the study of its cyclic stress-strain response using statistical theory of the hysteresis loop ${ }^{9}$ started a number of more thorough studies of this material. Transmission electron microscopy (TEM) was used to study the dislocation arrangement ${ }^{10}$, the sources of its extraordinary cyclic hardening ${ }^{11}$ and damage mechanisms at room and at elevated temperatures ${ }^{12-19}$. Further study was devoted to the damage mechanisms in thermomechanical fatigue ${ }^{20-25}$.

Previous papers on thermomechanical fatigue were devoted to in-phase and to out-of-phase cycling between temperature $200^{\circ} \mathrm{C}$ and $700^{\circ} \mathrm{C}$ with constant strain rates (IP-TMF and OP-TMF) ${ }^{20}$ and to in-phase cycling with dwell time in maximum tension (IPD-TMF) ${ }^{22,25}$. In this contribution the effect of the dwell period 
in a cycle applied in maximum compression (OPD-TMF) is studied. Cyclic stress-strain response, the internal structure evolution, the production and analysis of nanoprecipitates and the damage mechanisms are documented and discussed. The behaviour of the material in cycling with dwells in maximum compression is compared with previous results without dwell and with dwell in maximum tension. Electron microscopy investigation of the dislocation structure and precipitate distribution in specimens cycled with all four types of thermomechanical cycling is exposed. Also cyclic stress-strain curves and fatigue life curves for all four types of cycling are presented and discussed in terms of deformation and damaging mechanisms.

\section{Experimental}

\subsection{Material}

Superaustenitic heat resistant stainless steel Sanicro 25 grade UNS S31035 supplied by Sandvik, (Sweden) in the form of a cylindrical rod of $150 \mathrm{~mm}$ in diameter was investigated. The chemical composition of the material in wt. \% is $0.1 \mathrm{C}, 22.5 \mathrm{Cr}, 25.0 \mathrm{Ni}, 3.6 \mathrm{~W}, 1.5 \mathrm{Co}, 3.0 \mathrm{Cu}, 0.5 \mathrm{Mn}, 0.5 \mathrm{Nb}, 0.23 \mathrm{~N}, 0.2 \mathrm{Si}$ and the rest Fe. Semi-products of specimens having the diameter of $7 \mathrm{~mm}$ on the gauge length of $16 \mathrm{~mm}$ were manufactured parallel to the rod axis. Specimens were heat-treated by solution annealing at the temperature of $1200{ }^{\circ} \mathrm{C}$ for one hour and cooled in air. Later they were finished to the final dimensions. To facilitate the surface damage assessment, the gauge length of the specimens was mechanically and electrolytically polished.

\subsection{Mechanical testing}

Specimens were subjected to thermomechanical fatigue (TMF) loading in out-of-phase cycling with 10 min dwell in maximum compression (OPD-TMF). The dwell was thus applied at maximum temperature in a cycle. TMF experiments were carried out by means of computer-controlled servo-hydraulic mechanical testing MTS 880 system with hydraulic grips. More details on the high temperature thermomechanical testing can be found elsewhere ${ }^{25}$. In all cases mechanical strain $\epsilon$, mechanical strain amplitude $\epsilon_{a}$ or mechanical plastic strain amplitude $\epsilon_{a \pi}$ are reported. Hysteresis loops were recorded during cycling and plastic strain amplitude has been evaluated offline from the half of the width of the hysteresis loop.

\subsection{TEM internal structure investigation}

TEM was adopted for the study of the specimen internal structure. Thin plates were cut from the specimen gauge length parallel to the loading axis. The samples were mechanically grinded and once the thickness of $0.08 \mathrm{~mm}$ of the thin plate was reached, discs having a diameter of $3 \mathrm{~mm}$ were produced. Afterwards, discs were electrolytically polished utilizing a double jet device TenuPol5. The TEM foils were studied in high resolution TEM in scanning mode (STEM) along with EDS STEM (Oxford X-Max80) analysis of precipitates on Jeol JEM-2100F STEM operating at $200 \mathrm{kV}$.

\subsection{SEM, FIB and EBSD study of fatigue crack nucleation and growth}

The surface relief of cyclically strained specimens was studied by means of Tescan Lyra3 XMU FESEM equipped with a focused ion beam (FIB). The depths of secondary cracks were revealed by producing FIB trenches at the location chosen to find the in-depth profile of the crack. In addition to the damage evolution from the surface of the specimens, the internal damage was studied as well. In order to reveal the crack paths and chemical composition of the oxide layer the longitudinal sections parallel to the loading axis of specimens were produced. The longitudinal cuts were polished and the crack paths and their relation to the grain orientation were studied using electron back scatter diffraction (EBSD - Oxford Instruments). The chemical analysis of the oxide layer was documented utilizing energy dispersive spectroscopy (EDS - Oxford Instruments).

\section{Results}

3.1. Cyclic response of specimens subjected to TMF loading

During cyclic loading, all hysteresis loops were recorded and cyclic hardening/ softening curves are reported. Hysteresis loops in four types of thermomechanical cycling (IP-TMF, IPD-TMF and OP-TMF and OPD- 
TMF) between $250{ }^{\circ} \mathrm{C}$ and $700{ }^{\circ} \mathrm{C}$ with total strain amplitude $0.6 \%$ shows Fig. 1 . The first loop and the loop at half-life are shown. Since the dwell was always applied at the maximum temperature for IPD-TMF cycle it coincided with maximum tensile strain and for OPD-TFM cycle with maximum compression strain. In the first cycle, the hysteresis loops with the dwell do not significantly differ from those without dwell since the amount of relaxation is small. With increasing the number of cycles material cyclically hardens and the stress relaxation also becomes larger. This leads to the increase of the plastic strain range and also to the modification of the stress cycle asymmetry.

The evolution of the stress amplitude $\sigma_{a}$ plotted vs. the number of cycles $N$ of the material subjected to the OPD-TMF constant strain rate cycling shows Fig. 2. The cyclic response is characterized by rapid cyclic hardening from the onset of the cyclic straining. The pronounced cyclic hardening leads to the saturation of the stress amplitude for all total strain amplitudes (Fig. 2a). The domain of saturation takes more than $90 \%$ of the fatigue life. The final very rapid decrease of the stress amplitude is connected with the appearance of the dominant crack and the distortion of the shape of the hysteresis loop. The plastic strain amplitude vs. the number of cycles (Fig. 2b) decreases rapidly at the start of cycling. Later, at the number of cycles corresponding to maximum stress amplitude, the slope of the plot in semilogarithmic coordinates decreases. This decrease is for the majority of the fatigue life very mild and for high strain amplitudes plastic strain amplitude is nearly constant which corresponds to the saturation of the stress amplitude (see Fig. 2a). The evolution of the mean stress during OPD-TMF shows Fig. 2c. The initial slightly positive mean stress increases during the fatigue life up to $90 \mathrm{MPa}$. The rapid drop of the mean stress in the final stage of cycling is connected with the appearance of macroscopic crack.

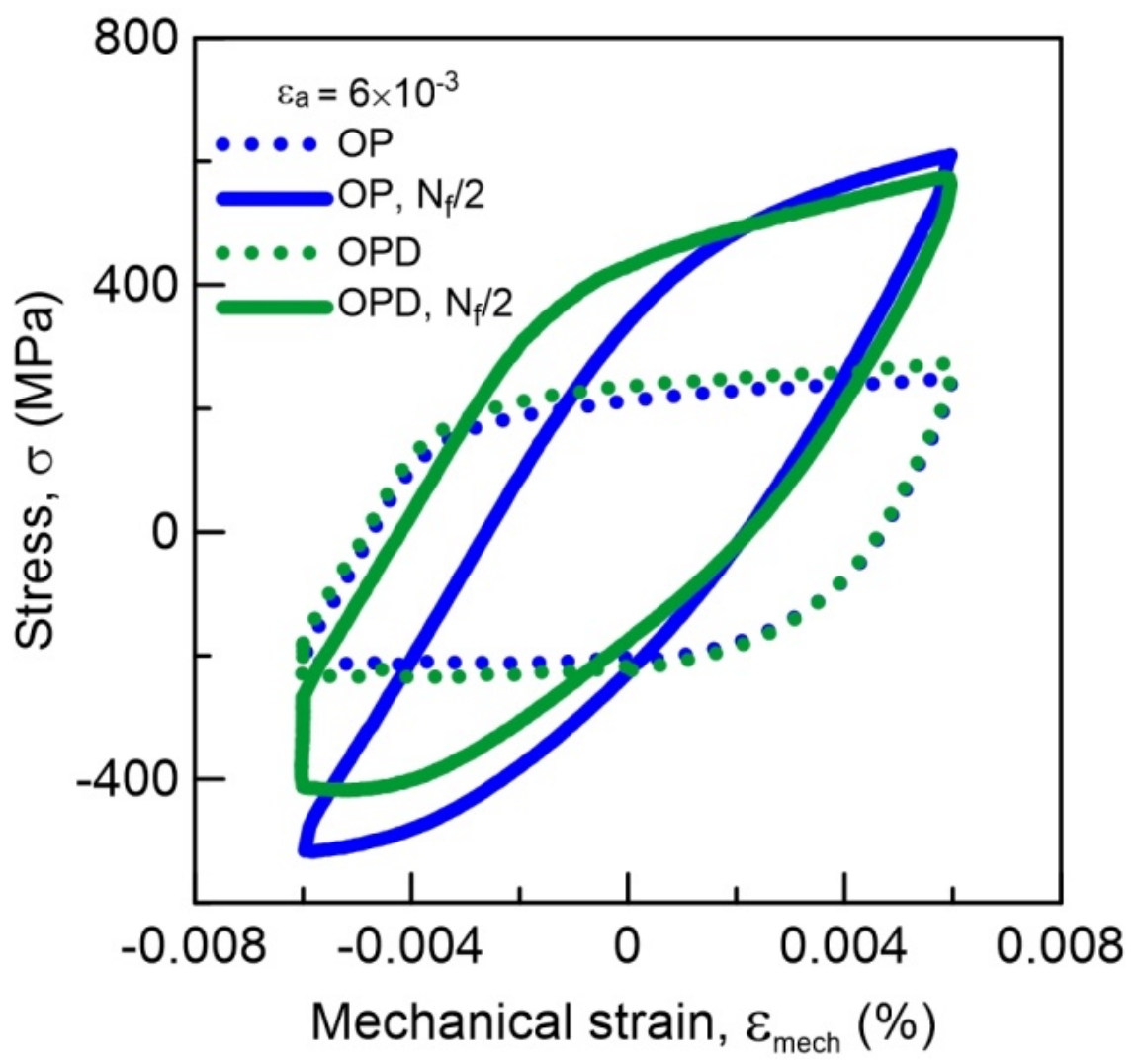




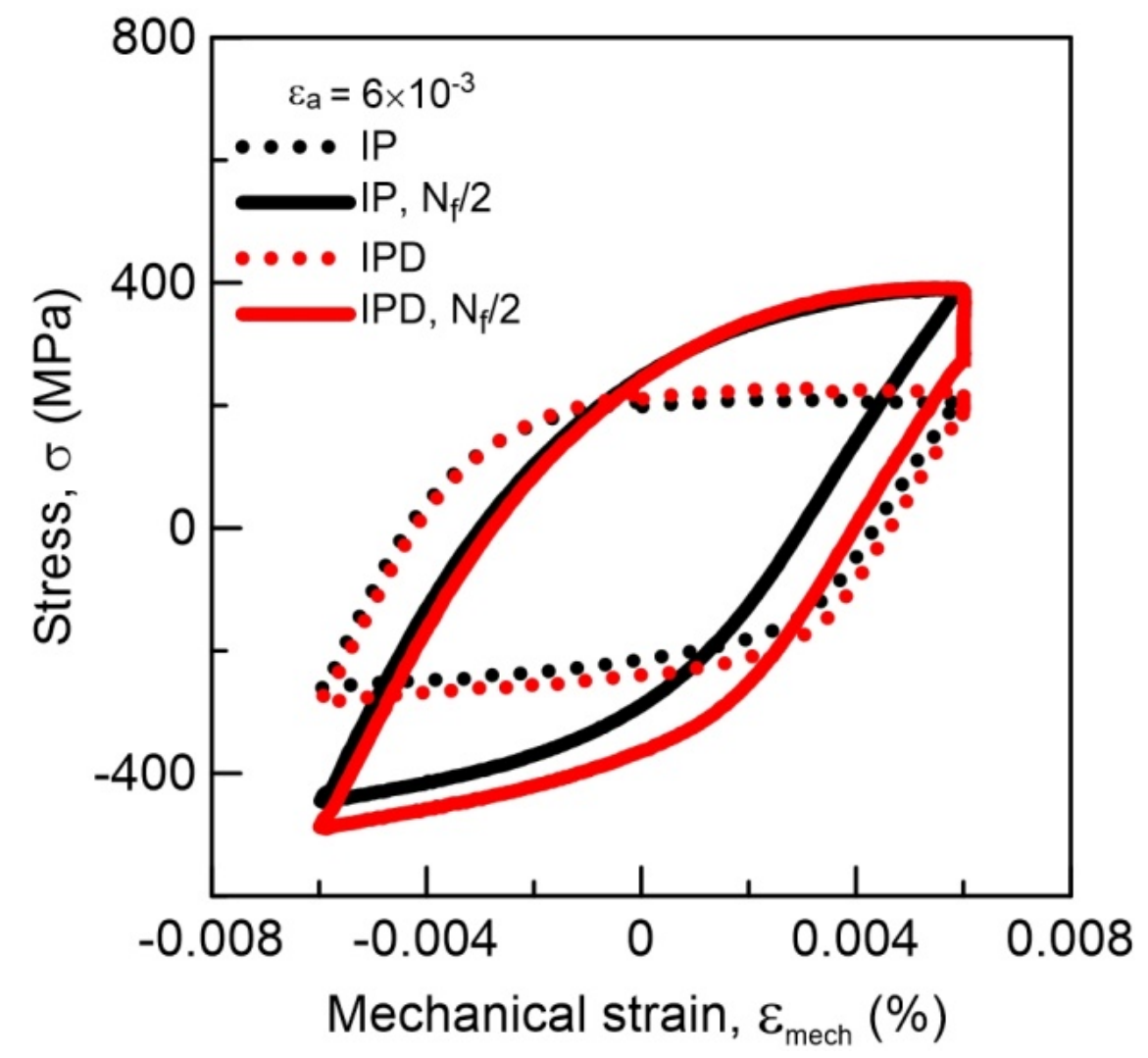

\section{(a) (b)}

Fig. 1. Stress-strain hysteresis loops for cycles $N=1$ and $\mathrm{N}=N_{f} / 2$ in TMF cyclic straining between 250 ${ }^{\circ} \mathrm{C}$ and $700{ }^{\circ} \mathrm{C}$ with total strain amplitude $0.6 \%$, (a) OP-TMF and OPD-TMF loading, (b) IP-TMF and IPD-TMF loading ${ }^{25}$. 


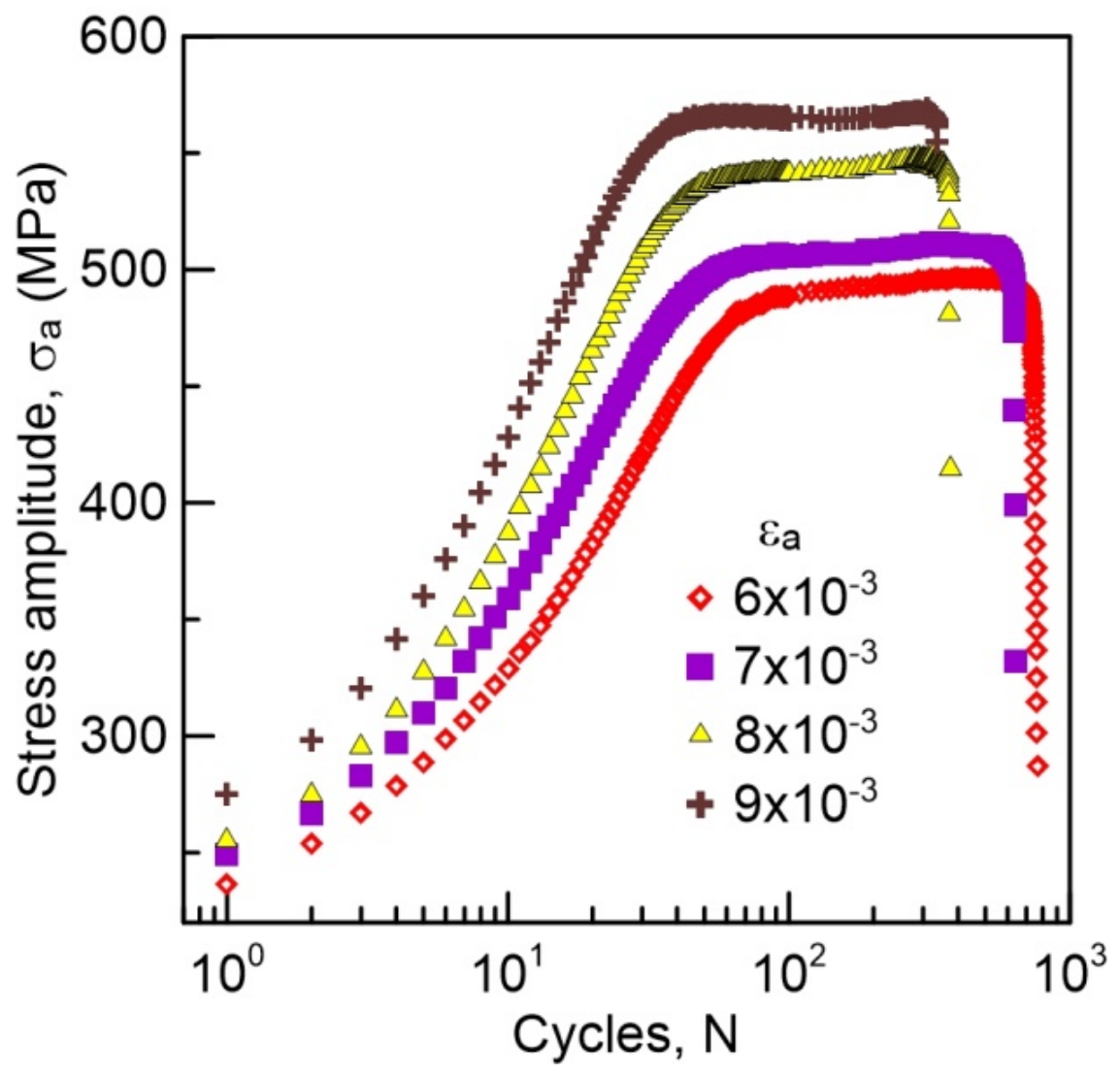




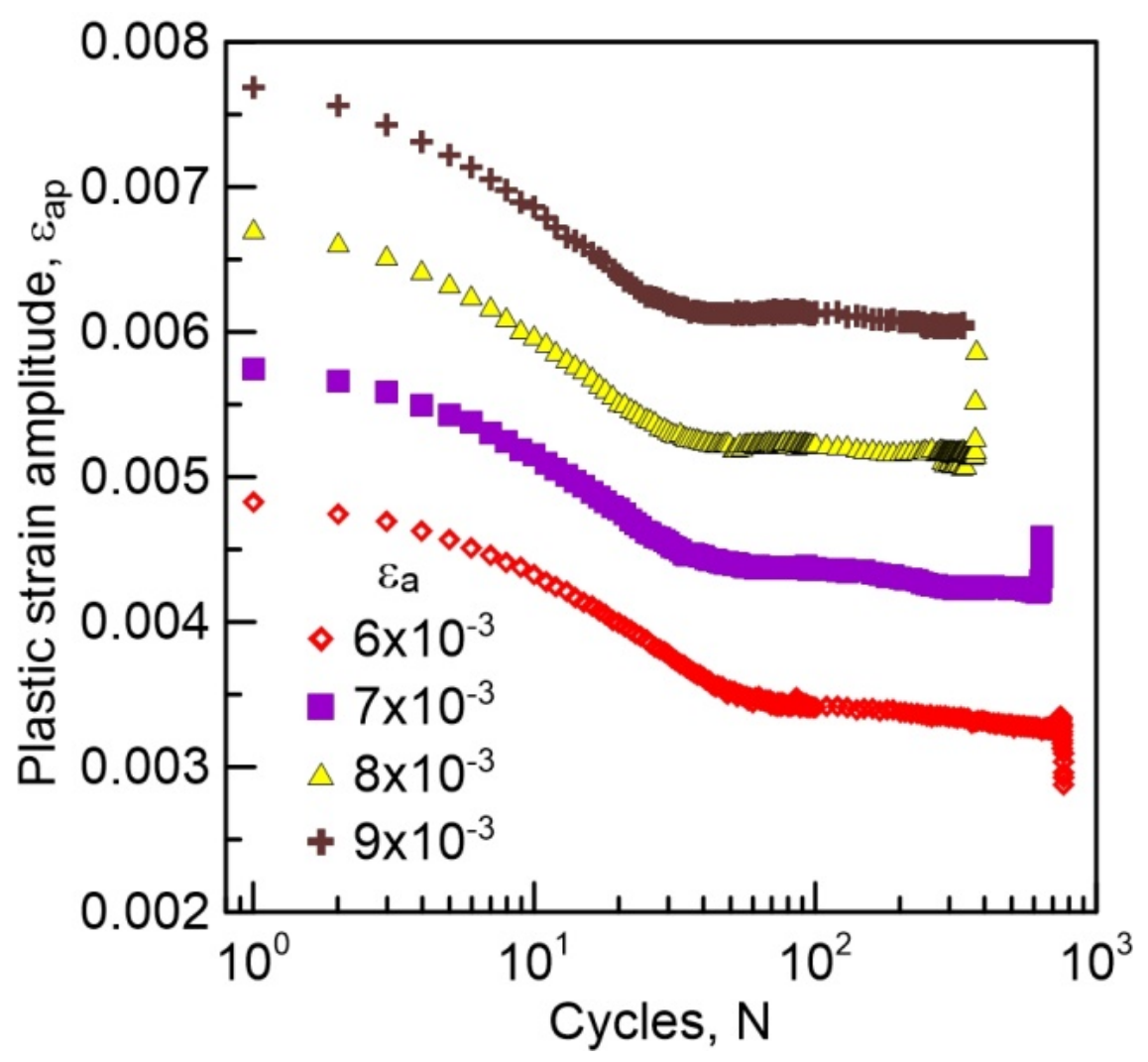

(a) (b) 


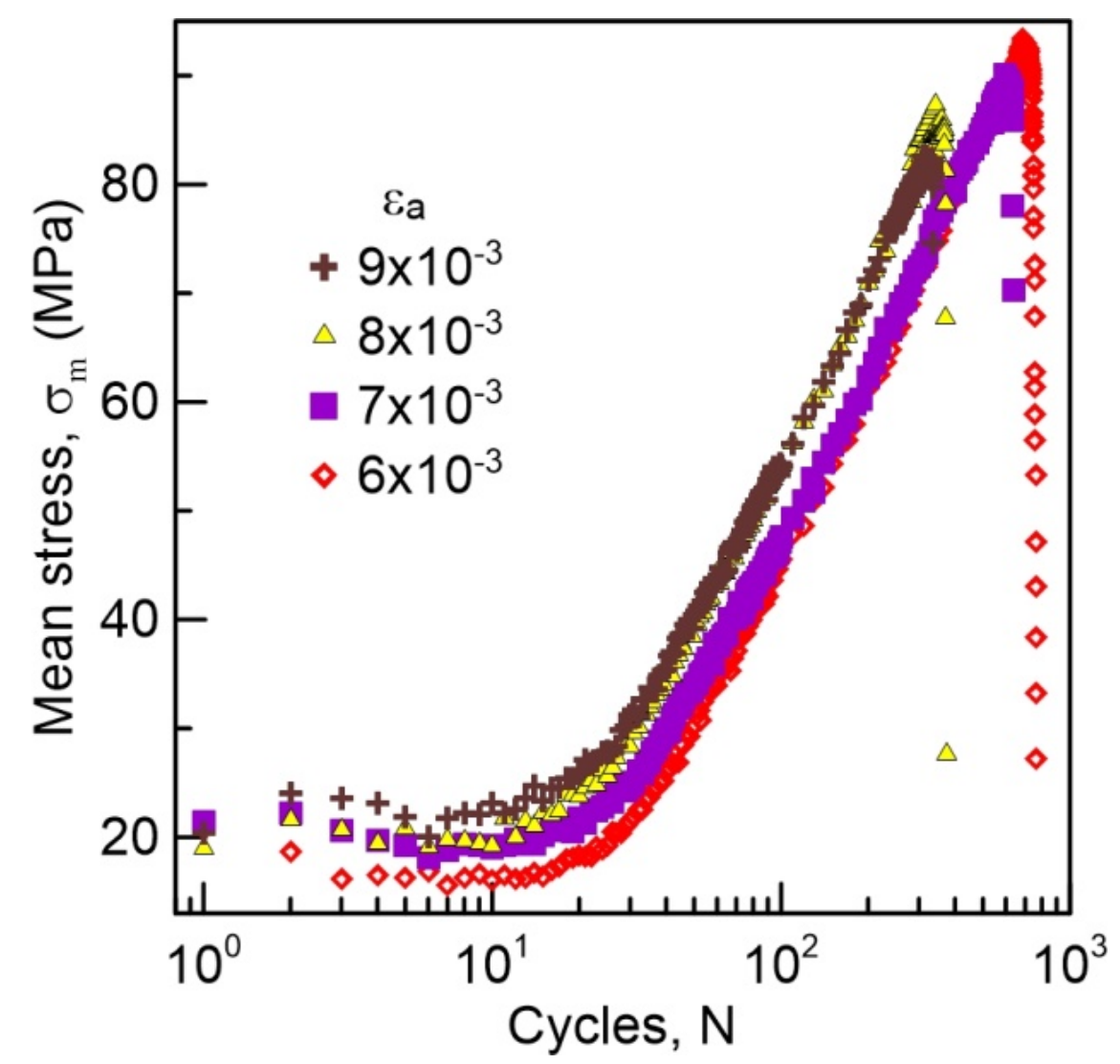

(c)

Fig. 2. Cyclic hardening/softening curves and mean stress in OPD TMF cycling for four strain amplitudes; (a) stress amplitude vs. the number of cycles, (b) plastic strain amplitude vs. number of cycles, (c) mean stress vs. the number of cycles.

Cyclic stress-strain curve from OPD-TMF tests is plotted in Fig. 3. For comparison also the cyclic stressstrain curves from IP-TMF, OP-TMF and IPD-TMF tests are shown here. Stress amplitude $\sigma_{a}$ is plotted vs. plastic strain amplitude $\epsilon_{a \pi}$, both at half-life. Cyclic stress-strain curves for OP-TMF and OPD-TMF cycling lies well above those for IP-TMF and IPD-TMF cycling and have higher slopes. The introduction of the dwell time at maximum temperature results in the shift of the cyclic stress-strain curves to lower stress amplitudes, both in IP and in OP cycling. This shift is more pronounced in OPD-TMF cycling.

\section{Hosted file}

image6.emf available at https://authorea.com/users/348369/articles/473725-the-effect-ofdwell-on-thermomechanical-fatigue-in-superaustenitic-steel-sanicro-25

Fig. 3. Cyclic stress-strain curves derived from TMF cycling tests with and without dwell.

\subsection{Microstructure}

The initial microstructure of this Sanicro 25 alloy (i.e. after annealing at $1200{ }^{\circ} \mathrm{C}$ for $1 \mathrm{~h}$ ) has been studied earlier by Heczko et al. ${ }^{10,11,26}$ and Warner et al. ${ }^{27}$. The average grain size of $60 \mu \mathrm{m}$ was determined by the intercept method; however, large grains of the size up to $200 \mu \mathrm{m}$ were present as well. The characteristic attribute of dislocation structure before applying cyclic loading is planar dislocation arrangement consisting 
of individual dislocations, stacking faults, pile-ups etc. Heczko et al. ${ }^{10}$ reported the formation of large particles rich in $\mathrm{Nb}$ and $\mathrm{Cr}$ identified as complex nitride $(\mathrm{Cr}, \mathrm{Nb}) \mathrm{N}$ i.e. Z-phase.

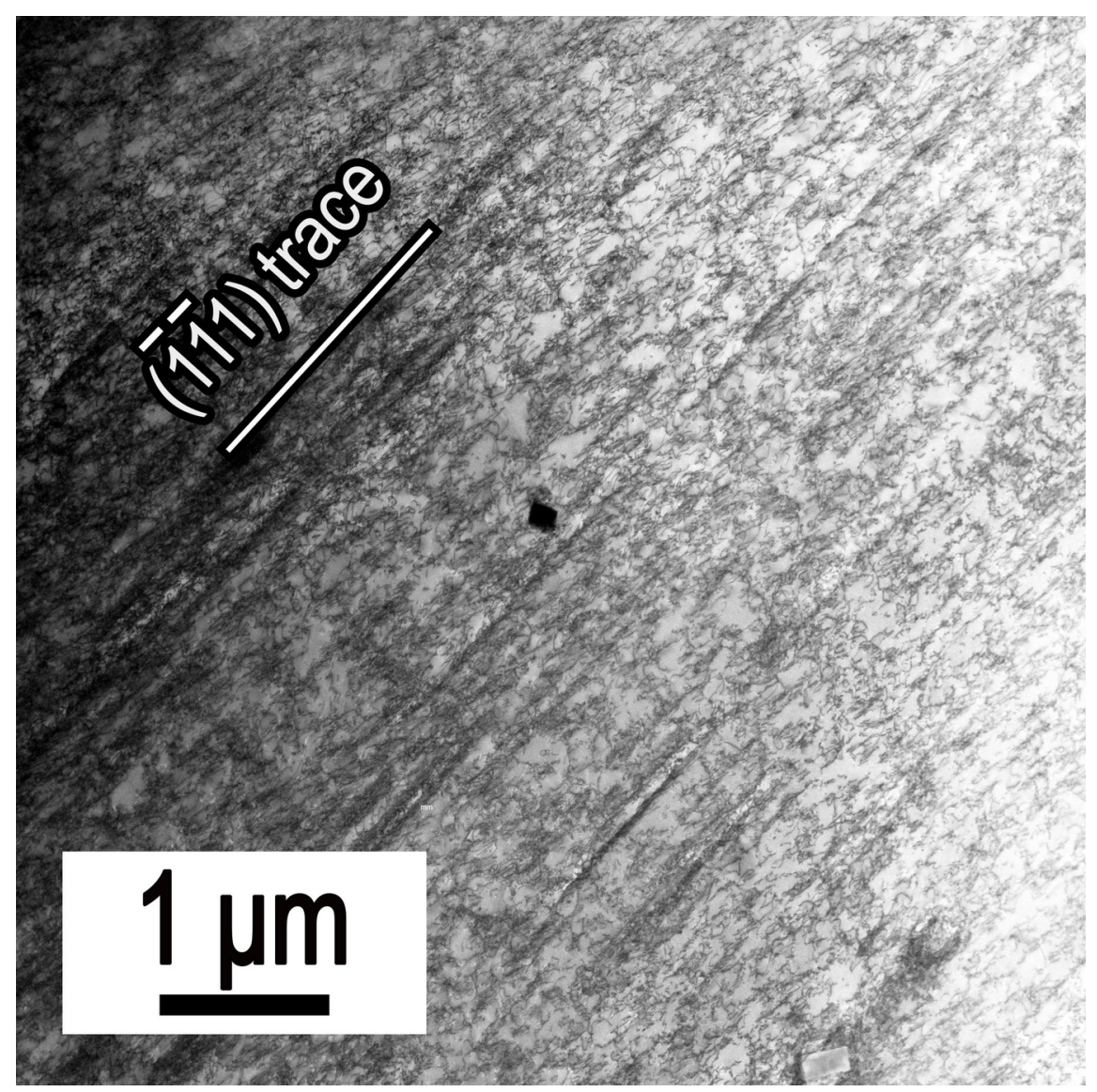




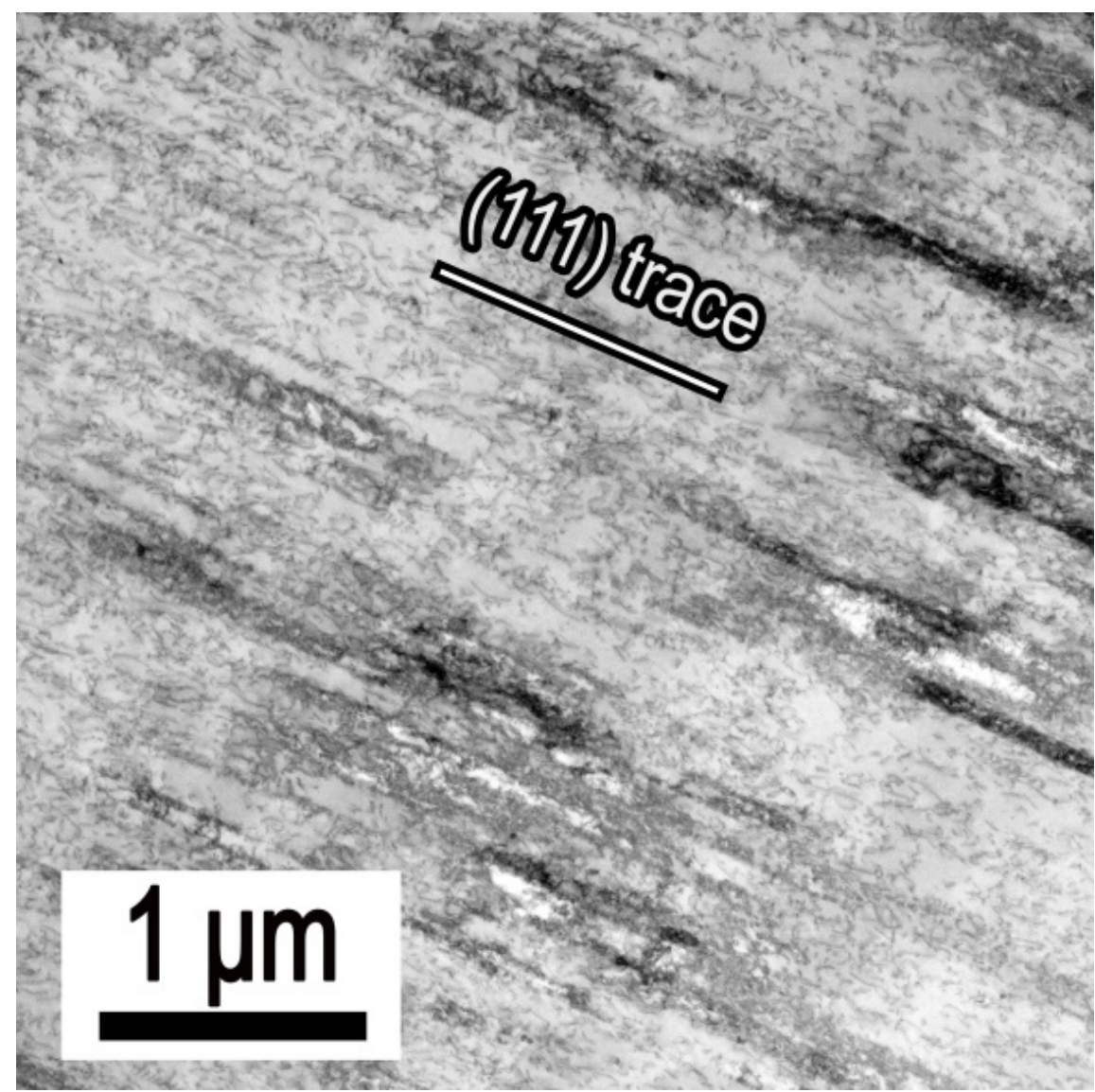

(a) (b) 


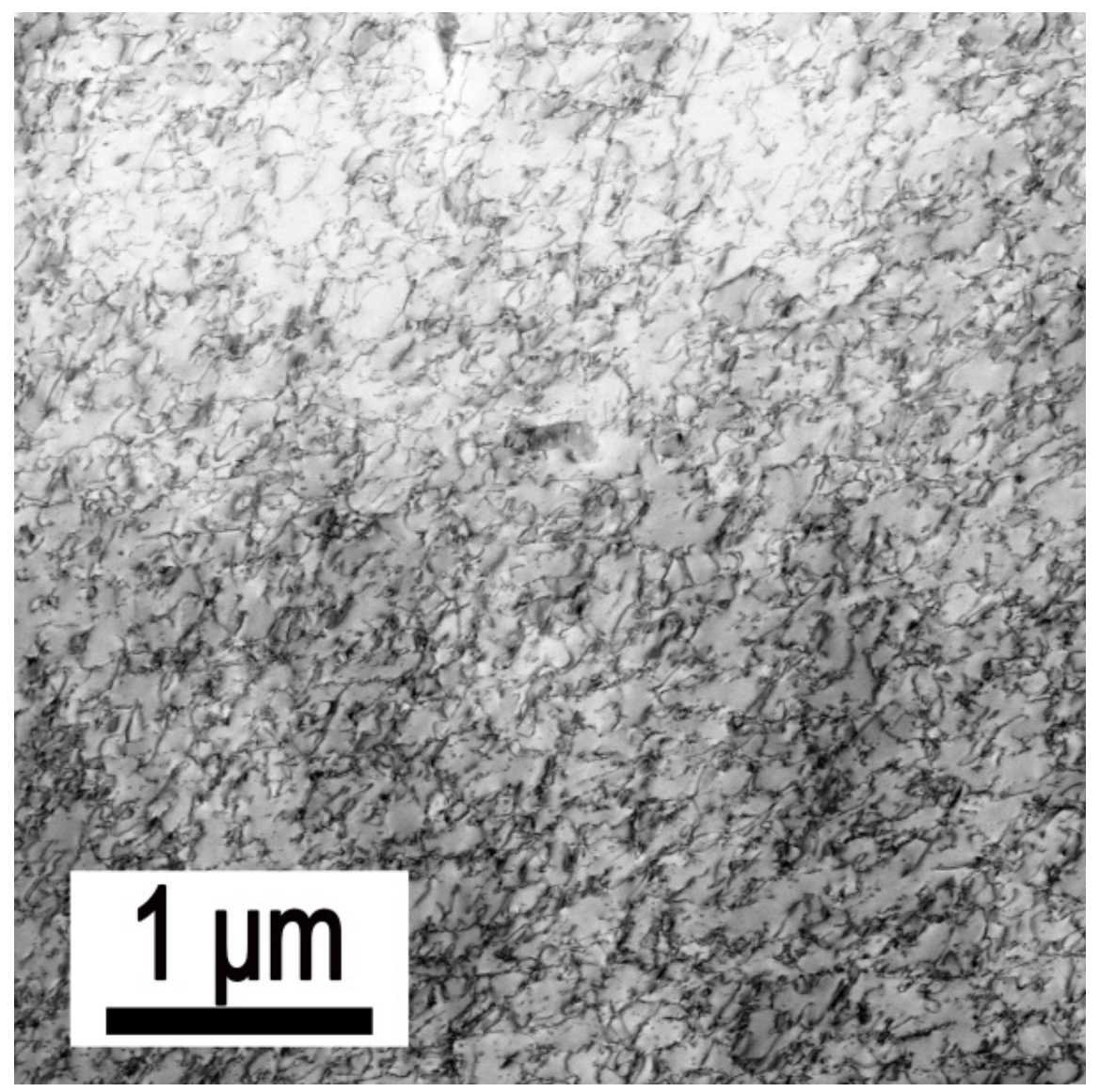




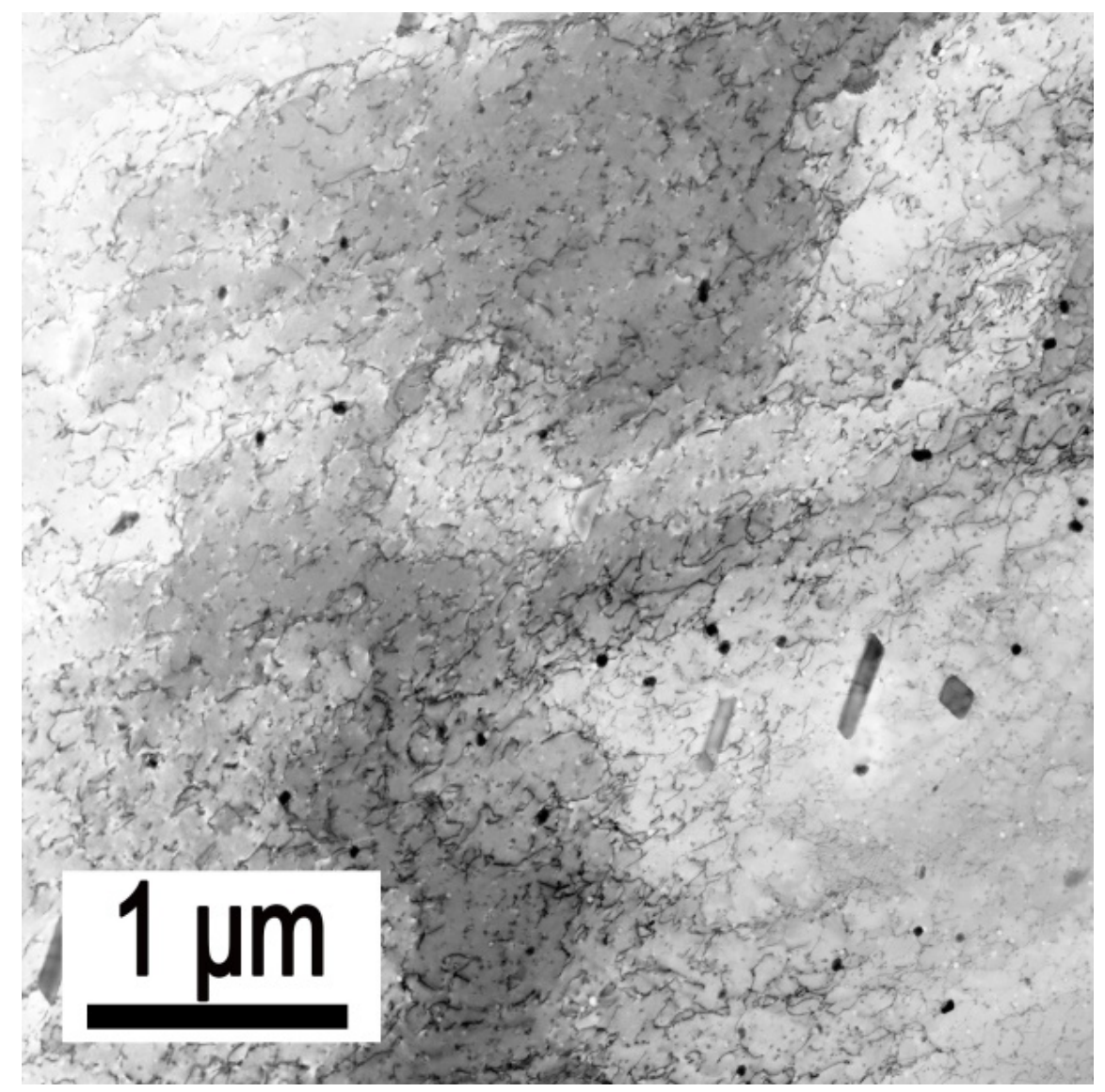

(c) (d)

Fig. 4. Typical dislocation structures observed in specimens subjected to TMF cycling with constant strain amplitude $6 \times 10^{-3}$ to fracture; (a) IP-TMF, (b) OP-TMF, (c) IPD-TMF, (d) OPD-TMF.

Here the microstructure in specimens subjected to different thermomechanical cycling using TEM in scanning mode (STEM) is reported. Fig. 4 documents bright field STEM micrograph of typical dislocation structures in specimens cyclically strained with total strain amplitude of $6 \times 10^{-3}$ to fracture in IP-TMF and OP-TMF as well as IPD-TMF and OPD-TMF loading procedures.

Cyclic loading at high temperature results in a pronounced increase of the dislocation density regardless of the testing conditions comparing to the initial state ${ }^{10}$. Similar dislocation arrangement was observed here in TMF without dwells. Fig. 4a and Fig. 4b show very high dislocation density with dislocations arranged in bands parallel to the trace of the slip plane of the primary slip system. Dislocation structure in specimens subjected to TMF with dwells differs significantly from those without dwells. Nearly random distribution of dislocation segments is typical for both loading procedures (Fig. 4c and Fig. 4d). The density of dislocations is lower in the case of TMF-OPD cycling than in the case of IPD-TMF cycling. Dislocation segments are often curved and are pinned by nanoparticles.

The extensive investigation of the dislocations structure of specimens cycled at high temperature by Heczko et al. ${ }^{11,26}$ was devoted to a detailed analysis of $\mathrm{Cu}$-rich and $\mathrm{NbC}$ particles formation and their influence on the mechanical response in constant strain rate cycling. Since the interaction of the dislocations with nanoparticles contributes significantly to the high resistance of the material at high temperature ${ }^{2,10,11,26}$ we have studied the occurrence of these particles in specimens subjected to different thermomechanical 
histories.

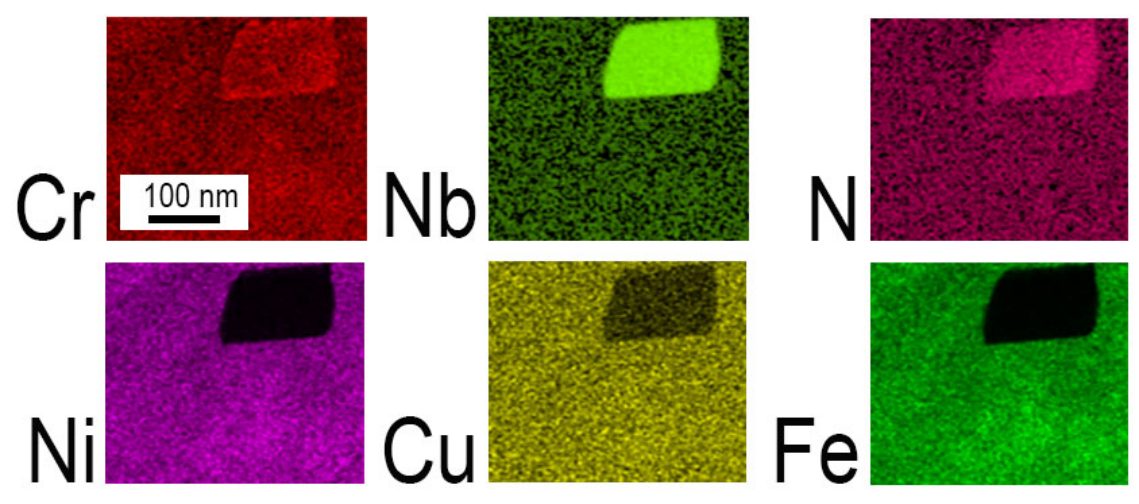

Fig. 5. STEM EDS map analysis of Z-phase particle observed in specimen strained under IP-TMF loading conditions. Coloured map documents that particle is rich on $\mathrm{Cr}, \mathrm{Nb}, \mathrm{N}$. On the contrary, Fe, $\mathrm{Ni}$ and $\mathrm{Cu}$ are highly depleted within the particle volume.

The STEM EDS analysis of the thin foil extracted from the specimen subjected to IP-TEM cycling in Fig. 5 shows the precipitate rich in $\mathrm{Cr}, \mathrm{Nb}$ and $\mathrm{N}$ and significantly depleted of $\mathrm{Fe}, \mathrm{Ni}$ and Cu. The composition of the particle corresponds to the Z-phase i.e. complex nitride $(\mathrm{Cr}, \mathrm{Nb}) \mathrm{N}^{2}, 10$ typically found in as-received condition. Thin foil and EDS map analysis in Fig. 6 shows the typical distribution of nanoparticles in the specimen subjected to IPD-TMF cycling. Larger particles contain copper and smaller particles contain niobium. In agreement with previous studies 11,26 the particles can be identified as a $\mathrm{Cu}-\mathrm{rich}$ and $\mathrm{NbC}$ nanoparticles which precipitated during TMF cycling.

The STEM image of the thin foil and respective EDS analysis map of the specimens subjected to OPD-TMF cycling shows Fig. 7. A high density of fine particles containing copper and still finer particles containing niobium is apparent. Moreover larger particles containing tungsten having lower density were detected.

Linescan performed on one of the large particles within the grain in Fig. 7 is shown in Fig. 8. While W dominates in the precipitate, a rapid decrease in $\mathrm{Cu}, \mathrm{Ni}$ and $\mathrm{Fe}$ content is clearly documented. According to Zurek et al. ${ }^{28}$ two diverse $\mathrm{W}$-rich phases can be identified in the interior of the grains as well as on the grain boundaries after high temperature exposure at $700{ }^{\circ} \mathrm{C}$ and $750{ }^{\circ} \mathrm{C}$ for 3000 h. Tungsten rich carbide of the type $(\mathrm{Cr}, \mathrm{W})_{23} \mathrm{C}_{6}$ and/or $(\mathrm{Fe}, \mathrm{W})_{6} \mathrm{C}$ can be one of these phases and $\mu$-phase Fe7W6 can be the second one. Both phases were found to be located at the grain boundaries and also in the interior of the grains. The same kind of precipitates was observed in specimens exposed to temperature $700{ }^{\circ} \mathrm{C}$ for $10000 \mathrm{~h}$. 


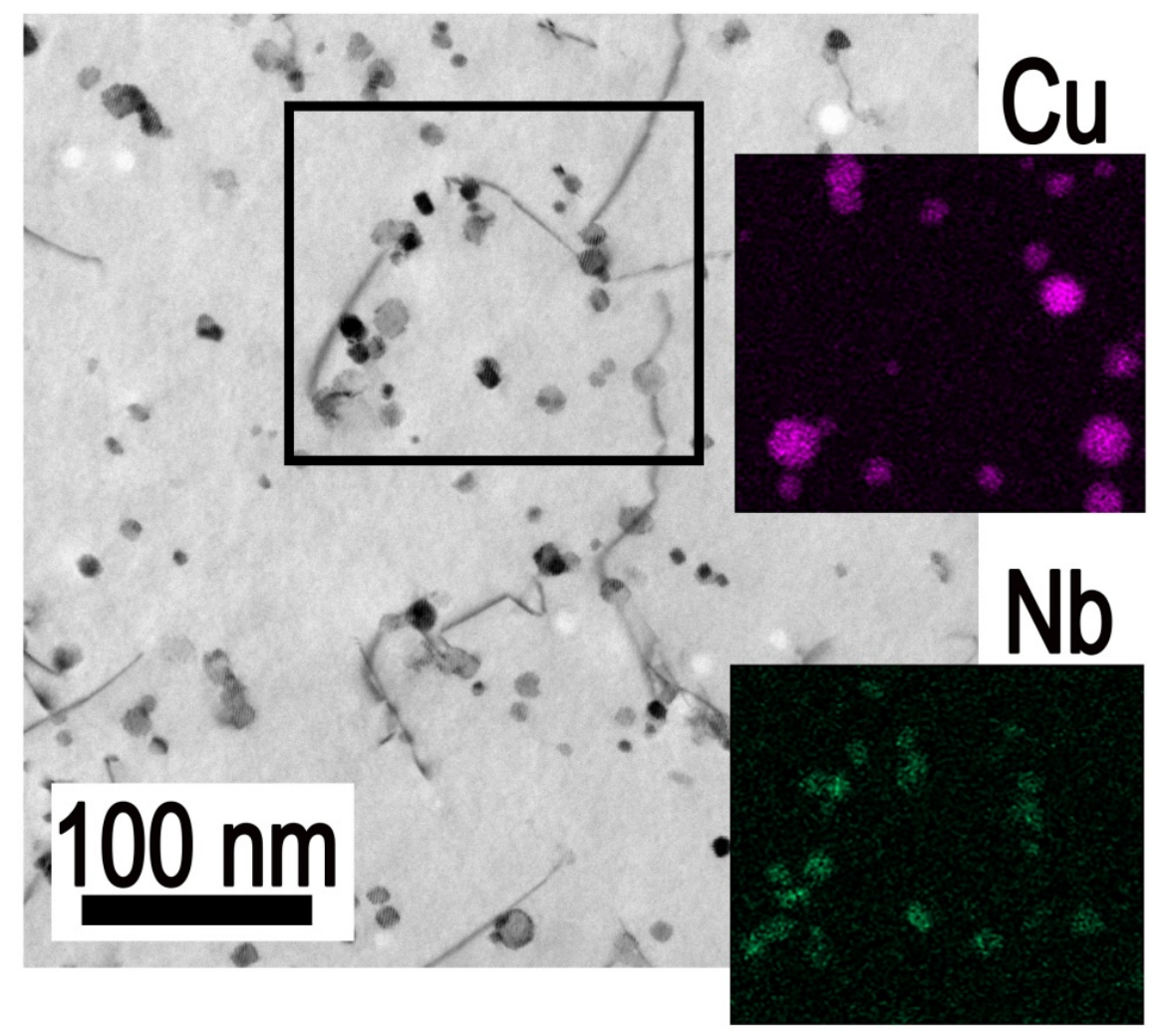

Fig. 6. STEM and EDS map analysis in the specimen subjected to OPD-TMF procedure with strain amplitude $6 \times 10^{-3}$. Two types of particles are found. Larger particles containing copper and smaller particles containing niobium. 


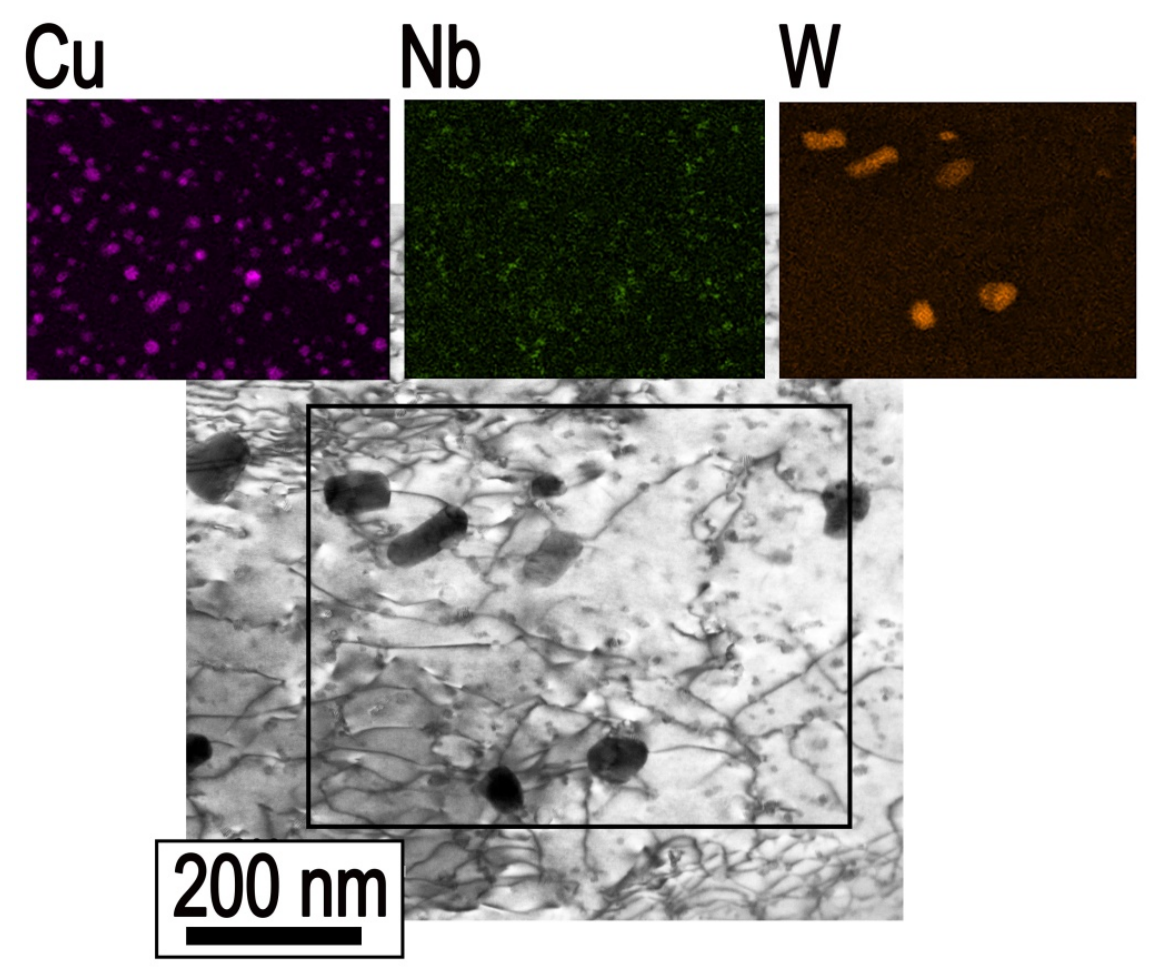

Fig. 7. Microstructure of the specimen subjected to OPD-TMF procedure with constant strain amplitude $6 \times 10^{-3}$. Chemical analysis of individual particles. EDS analysis of respective $\mathrm{Cu}, \mathrm{Nb}, \mathrm{W}$ content (bright areas correspond to high element concentration) 


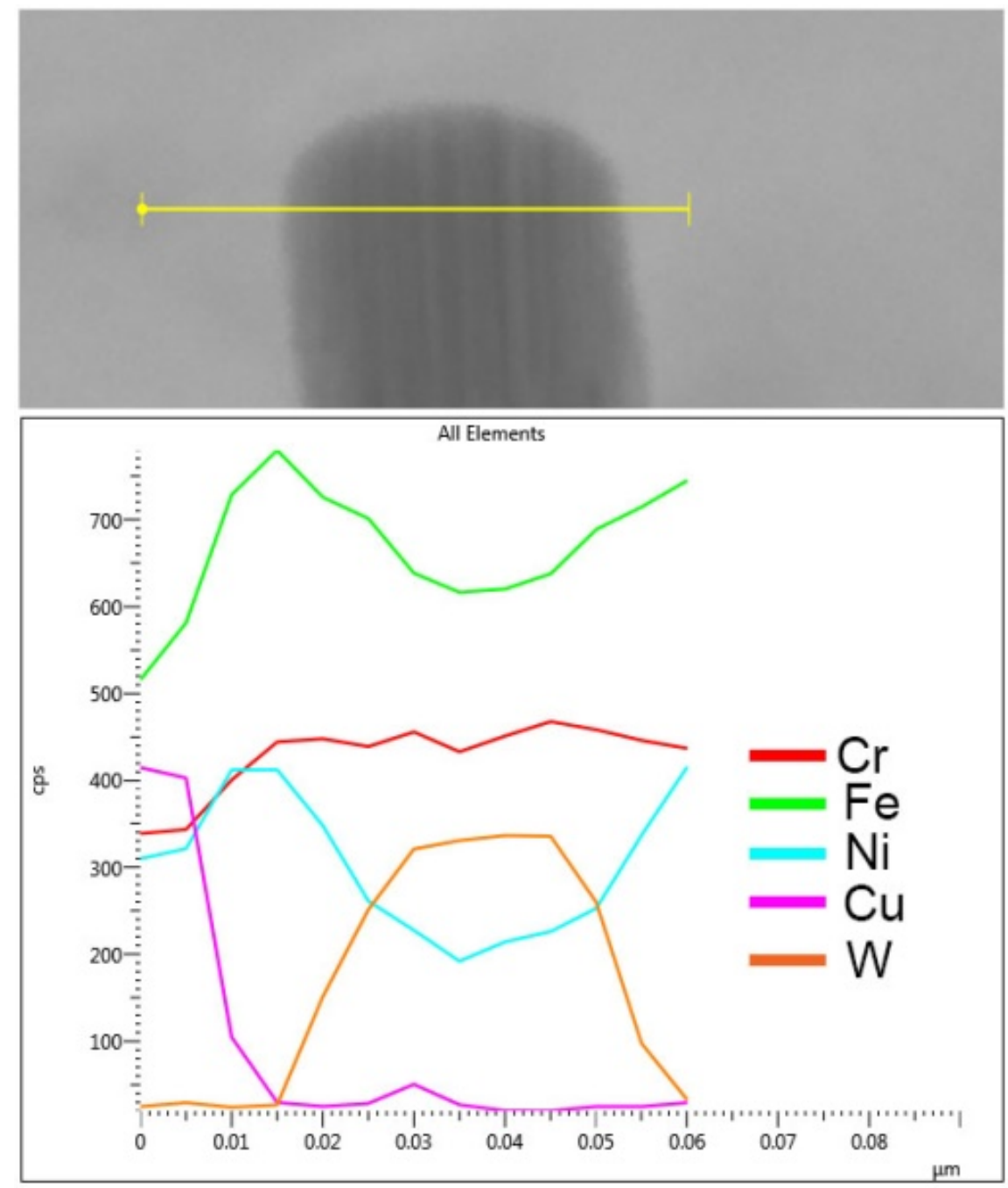

Fig. 8. STEM EDS linescan through the particle present in the grain interior. Mainly W is rich within the particle, while content of $\mathrm{Fe}, \mathrm{Ni}$ and $\mathrm{Cu}$ is significantly depleted or absent.

Fig. 9 shows the STEM image of the foil and the EDS map illustrating the composition of particles developed at the grain boundaries and in its neighbourhood. EDS analysis indicates the formation of Cr-rich particles decorating the grain boundary. The area close to the grain boundary is rich in $\mathrm{Cr}$ and is heavily depleted in $\mathrm{Fe}$ and $\mathrm{Ni}$. In steels having the essential content of $\mathrm{Cr}$, there is a strong tendency to the rapid formation of numerous Cr-rich particles of $\mathrm{M}_{23} \mathrm{C}_{6}$ type ${ }^{29} \cdot \mathrm{M}_{23} \mathrm{C}_{6}$ particles nucleate rapidly preferentially at high angle grain boundaries which is in accord with the results of Mazánová et al. ${ }^{14}$. Fig. 9 also shows the chains of Curich particles and small-scale Nb-rich particles nucleated at the grain boundary. Cu-rich particles nucleated at the grain boundary are substantially larger than those in the matrix. 


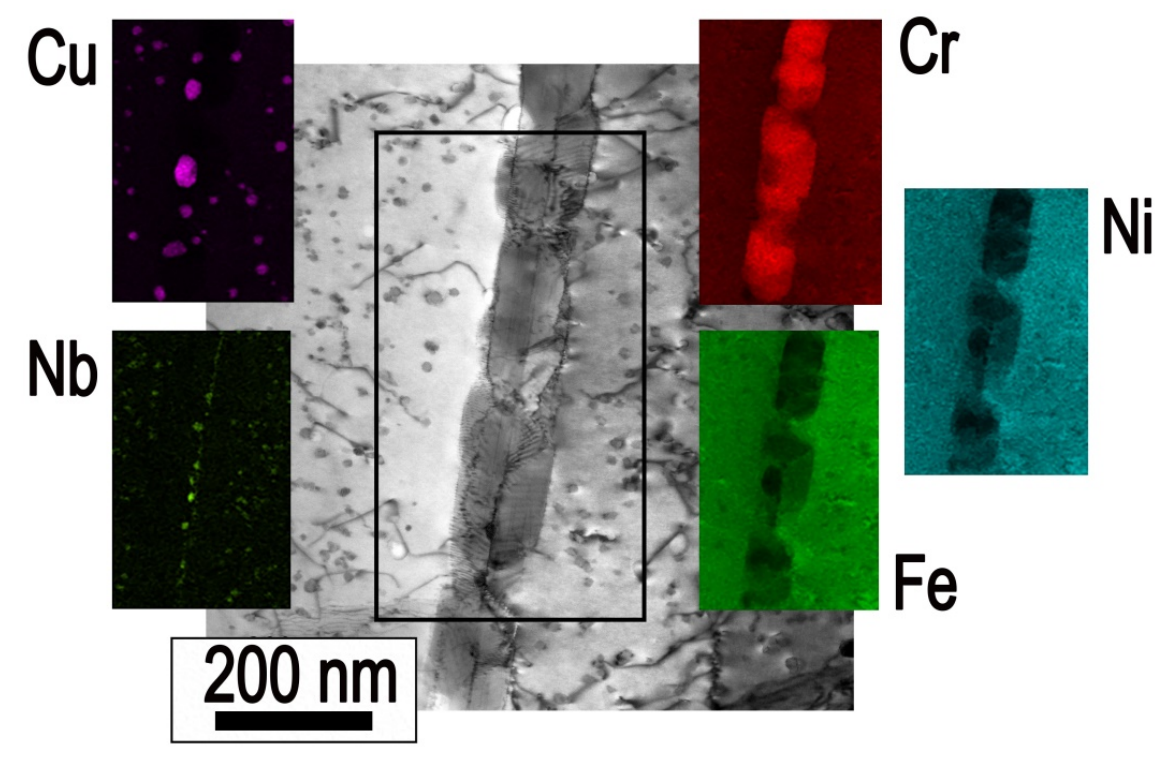

Fig. 9. STEM image of the grain boundary. Marked area was subjected to EDS analysis. $\mathrm{M}_{23} \mathrm{C}_{6}$ Cr-rich carbides nucleated at the grain boundary along with $\mathrm{Cu}$ - and Nb-rich particles are documented. Location of $\mathrm{M}_{23} \mathrm{C}_{6} \mathrm{Cr}$-rich carbides is depleted in $\mathrm{Fe}$ and $\mathrm{Ni}$ content.

\subsection{Damage mechanisms in-phase thermomechanical fatigue with dwells}

Fatigue damage in thermomechanical loading started by oxidation of the surface. Thin surface oxide layer has been formed with enhanced oxidation at the grain boundaries. Preferentially the boundaries which were on the surface perpendicular to the loading axis were heavily oxidized and oxide extrusions prolapse on the surface. Preferential oxidation continued along the grain boundary (in IP-TMF cycling) and fatigue crack has been formed similarly to the case of high temperature fatigue loading ${ }^{8}$. In the case of thermomechanical fatigue loading without dwells ${ }^{20}$, cracks arise due to cracking of the thick oxide layer in the tensile part of the cycle. In order to find the effect of the dwells the surface relief of the specimens subjected to the IPD-TMF and OPD-TMF at the end of the fatigue life was studied and compared with that during TMF cycling without dwells.

\subsubsection{IPD-TMF cycling}

Fig. 10a represents the surface of the specimen subjected to IPD-TMF cycling with total strain amplitude $6 \times 10^{-3}$. Oxide layer formed on the specimen surface can be easily recognized along with the bands of the thicker oxide developed preferentially at the grain boundaries. The early fatigue cracks initiated exclusively due to cracking of the highly oxidized grain boundaries, preferentially those which were on the surface oriented perpendicularly to the stress axis.

The in-depth profile of the secondary crack is imaged in Fig. 10b. The oxidation and cracking of the oxidized grain boundary are essential in terms of crack formation. The crack here follows the grain boundary perpendicularly to the loading axis. Since oxygen diffusion and also subsequent oxidation of the crack tip are temperature and time dependent the 10 minute tensile dwell during high temperature exposure of the opened crack to the air results in the increase of oxidation rate. Subsequently, the oxidation and cracking follow the grain boundary as documents the longitudinal cut of a specimen subjected to IPD-TMF cycling in Fig. 11. SEM image in Fig. 11a shows the crack developed from the specimen surface propagating through the material volume. The respective EBSD image in Fig. 11b reveals intergranular crack growth. 

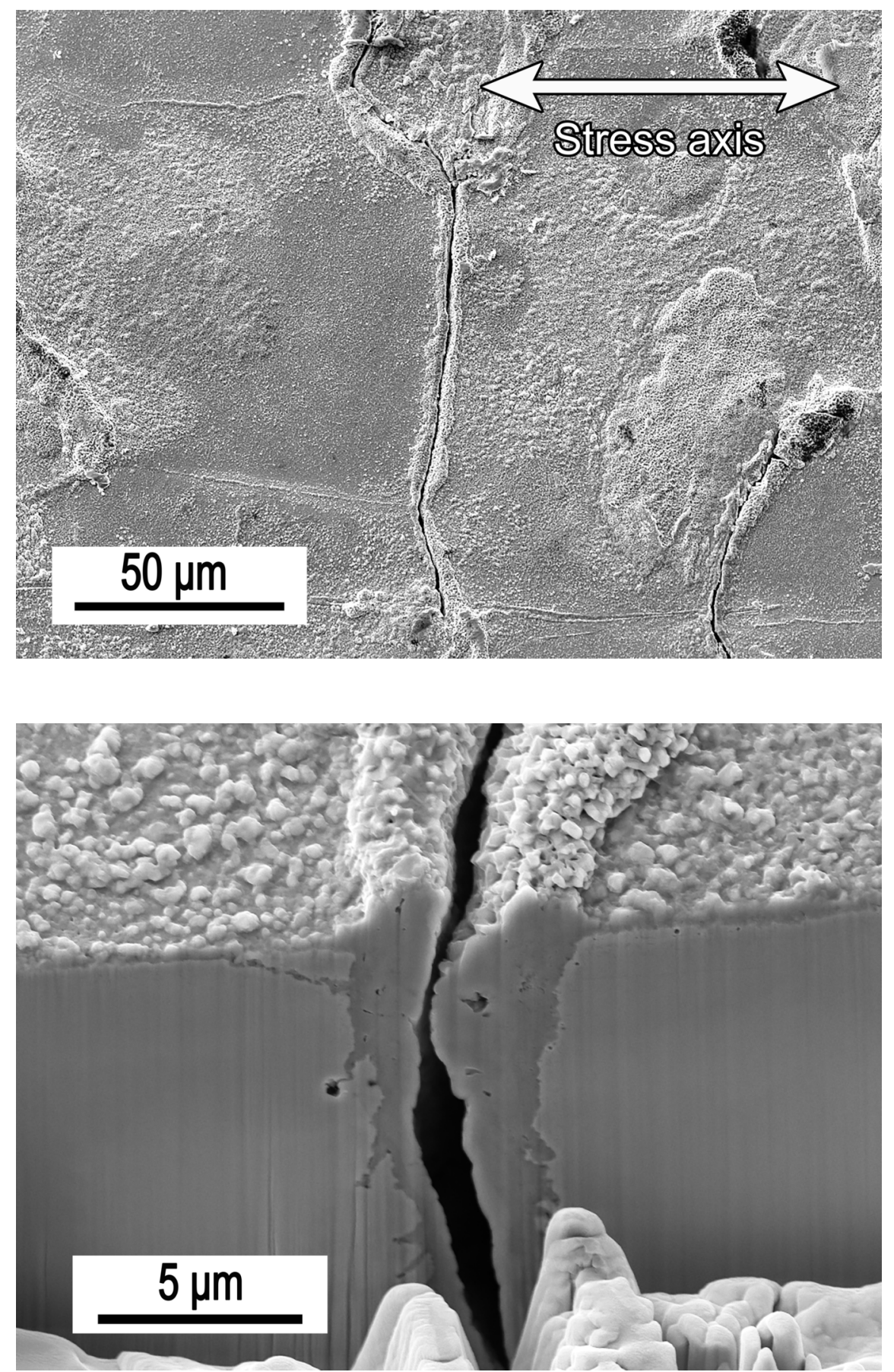

(a) (b)

Fig. 10. Specimen cyclically strained under IPD-TMF conditions with mechanical strain amplitude $6 \times 10^{-3}$ to fracture; (a) SEM image of the surface, (b) FIB cut perpendicular to the surface and to the stress axis; cracked and oxidized grain boundary. 


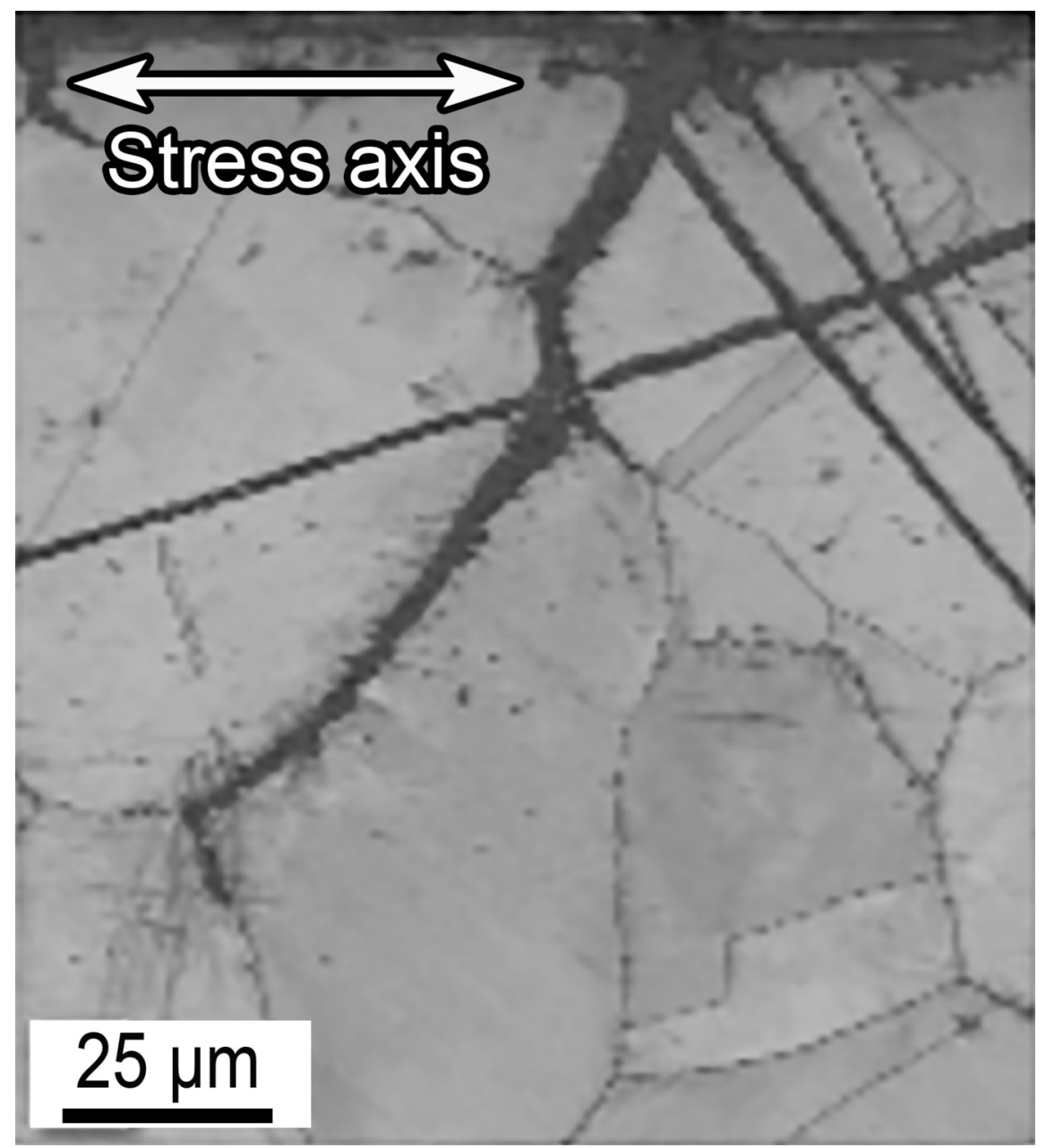




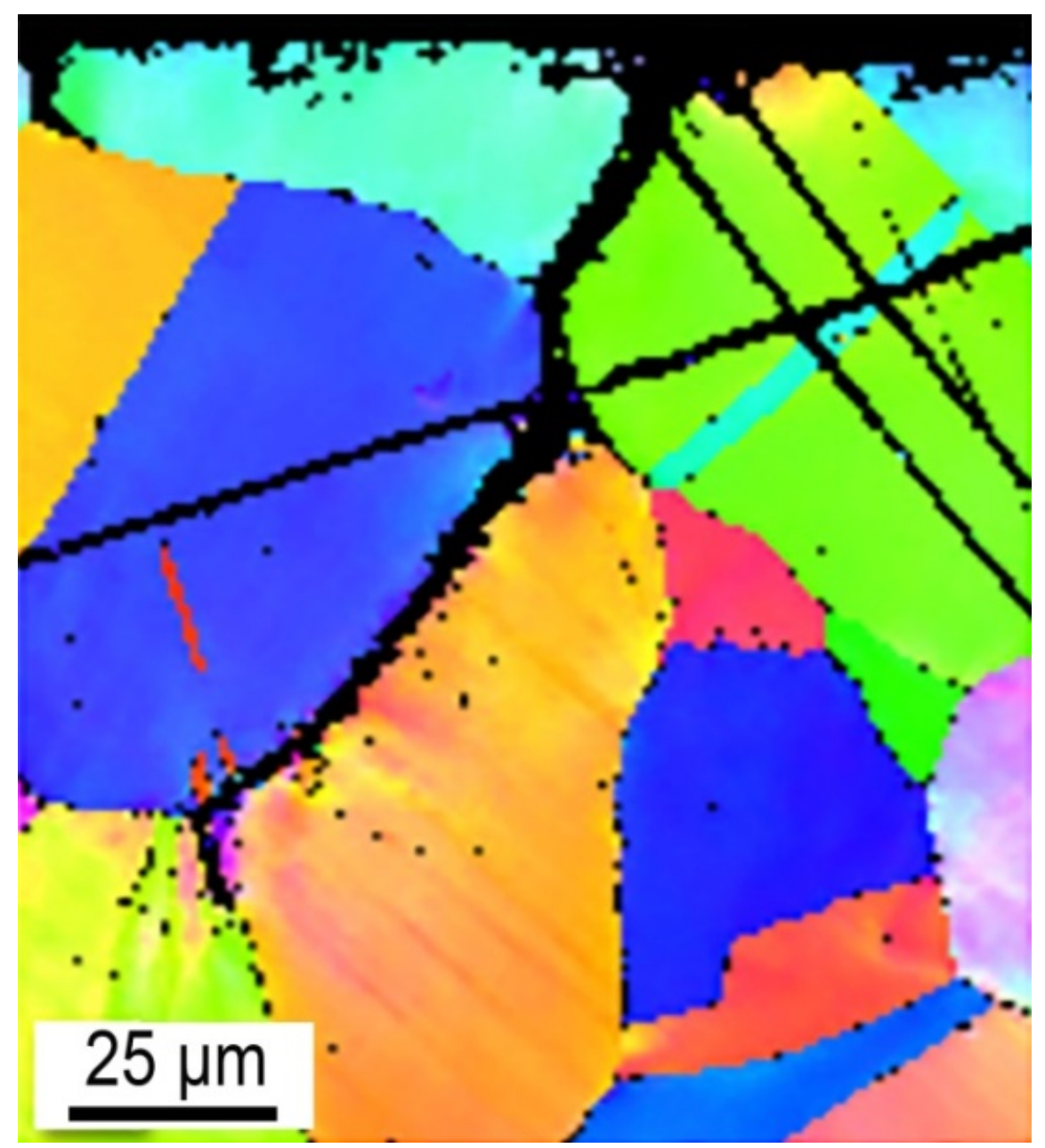

(a) (b)

Fig. 11. Longitudinal section of the specimen subjected to IPD-TMF cycling with mechanical strain amplitude $6 \times 10^{-3}$ to fracture; (a) SEM image, (b) EBSD image.

Introduction of the tensile dwell to the loading cycle led also to the formation of the internal damage referred to as creep deterioration. Internal cracks developed during IPD-TMF cycling are documented on the longitudinal section of a specimen in Fig. 12. EBSD image in Fig. 12b reveals that the internal cracks follow the grain boundaries. The internal damage may significantly influence the growth of the dominant fatigue crack due to interaction of this crack with the internal cracks which were nucleated close to the crack tip. The joining of the dominant crack with internal cracks accelerates the crack growth. 


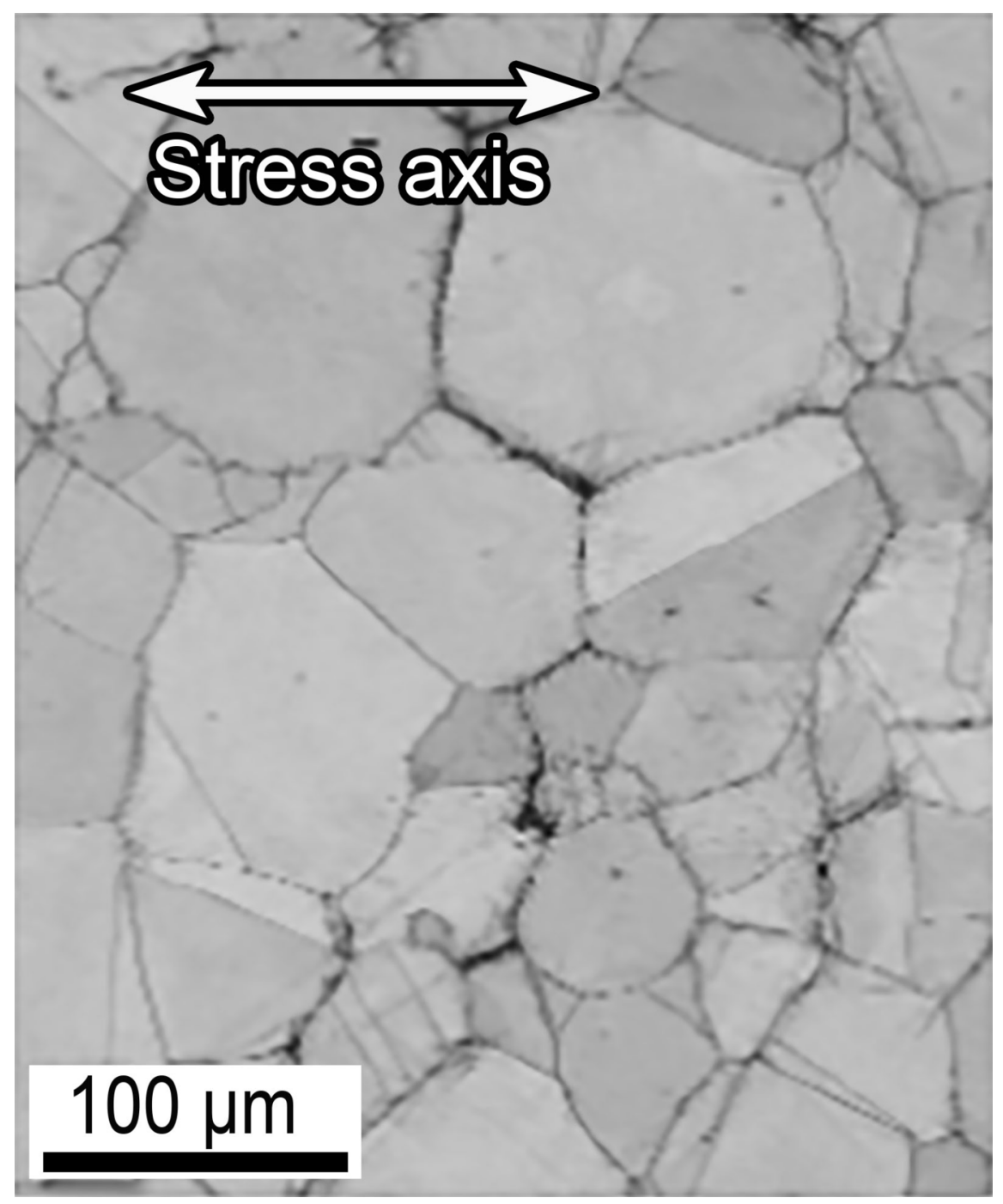




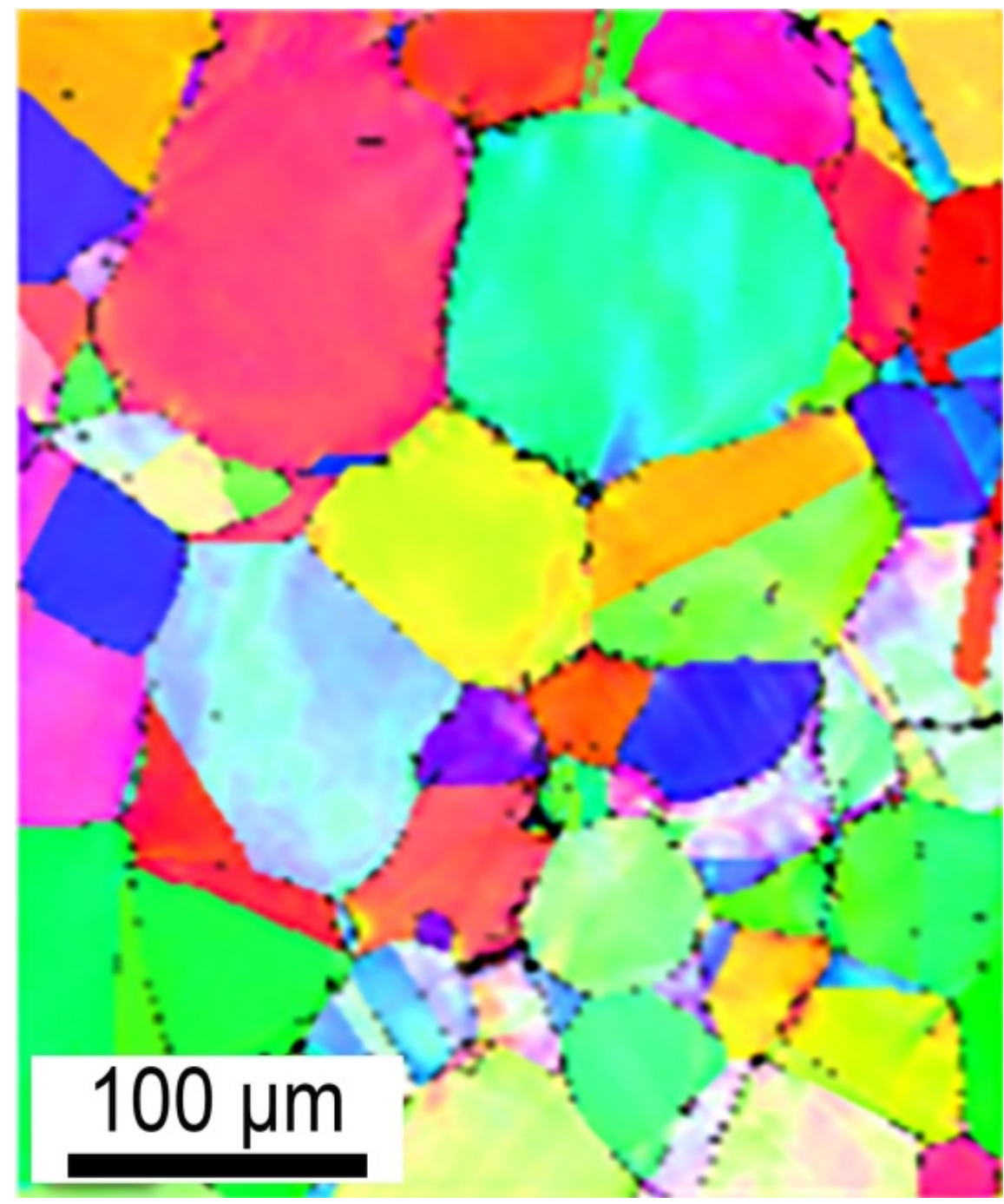

(a) (b)

Fig. 12. Longitudinal cross section of specimen subjected to IPD-TMF showing internal damage development; (a) band contrast, (b) EBSD image.

\subsubsection{OPD-TMF cycling}

The previous results on the damage evolution in OP-TMF cycling ${ }^{20}$ revealed substantially different damage mechanism than in IP-TMF cycling. The cracks started much later than in IP-TMF cycling, i.e. only when a thick oxide layer was formed on the specimen surface. The thick oxide layer cracked perpendicularly to the stress axis. Similar damage mechanism was present in OPD-TMF cycling. The surface relief of the specimens exposed to OPD-TMF loading with total strain amplitude $6 \times 10^{-3}$ is presented in Fig. 13. The specimen surface is highly oxidized and moreover the islands of thicker oxide layers can be distinguished within some grains. The cracks developed mainly in the islands of the thick oxide layer and are again oriented perpendicularly to the stress axis. The cracks in the oxide are well open. The crack in the grain boundaries appeared as well but the fraction of grain boundary cracking was smaller in comparison to the transgranular crack formation on the thick oxide layer. 


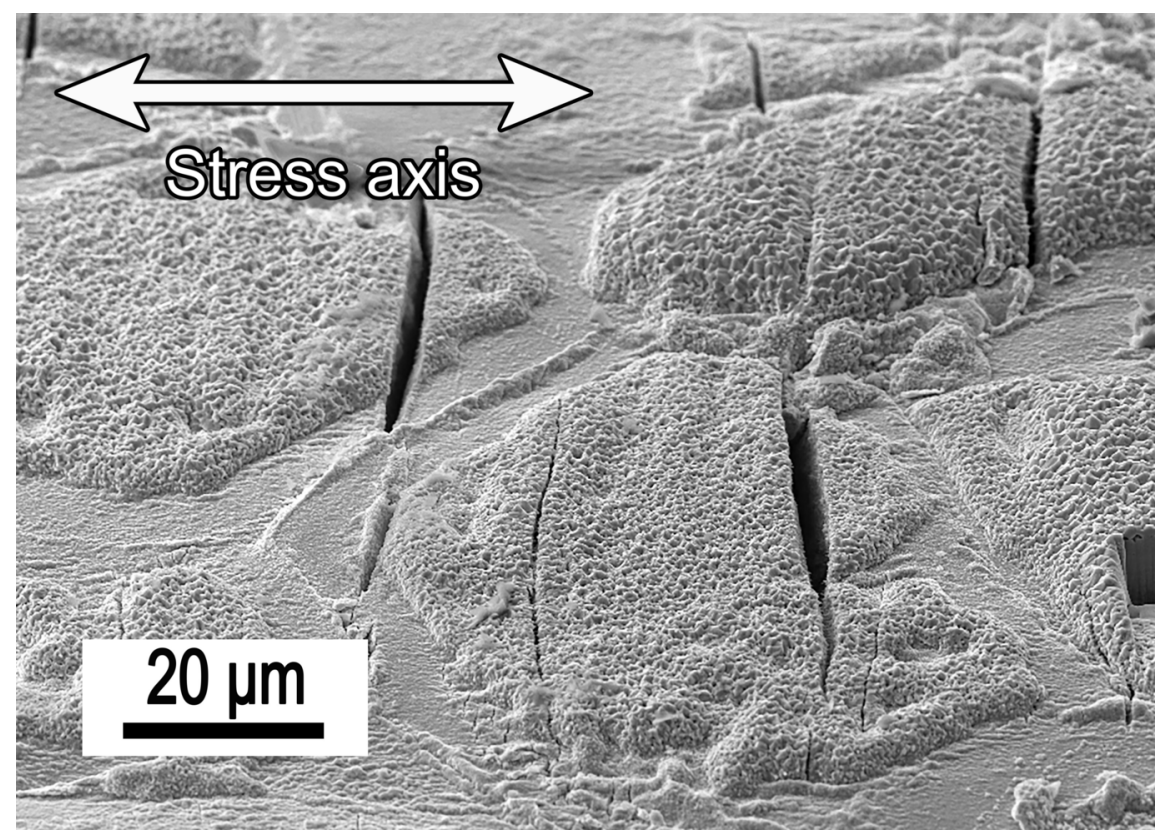

Fig. 13. Surface of the specimen cyclically strained under OPD-TMF cycling with mechanical strain amplitude $6 \times 10^{-3}$ to fracture.

FIB cross section of two secondary cracks starting in the thick oxide layer is presented in Fig. 14. The fatigue crack initiated from the thick uniform oxide layer propagated through the oxide to the matrix. Fig. 14a shows the thick oxide layer which is cracked. The crack facilitates the access of the oxidizing atmosphere to the metal surface around the crack tip which facilitates further oxidation and following crack growth. The crack in Fig. 14b also started in the thick oxide layer and by alternating oxidation close to the crack tip and cracking of the oxide propagated deep in the material.

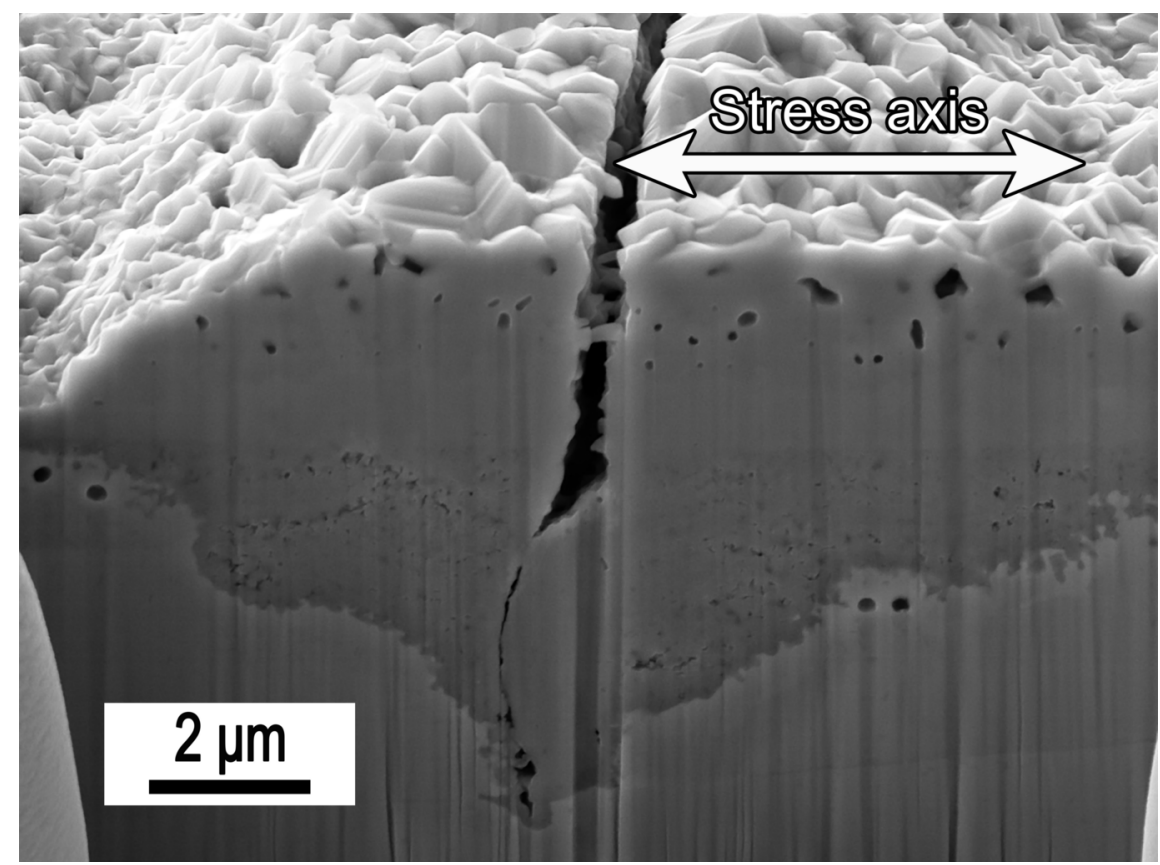




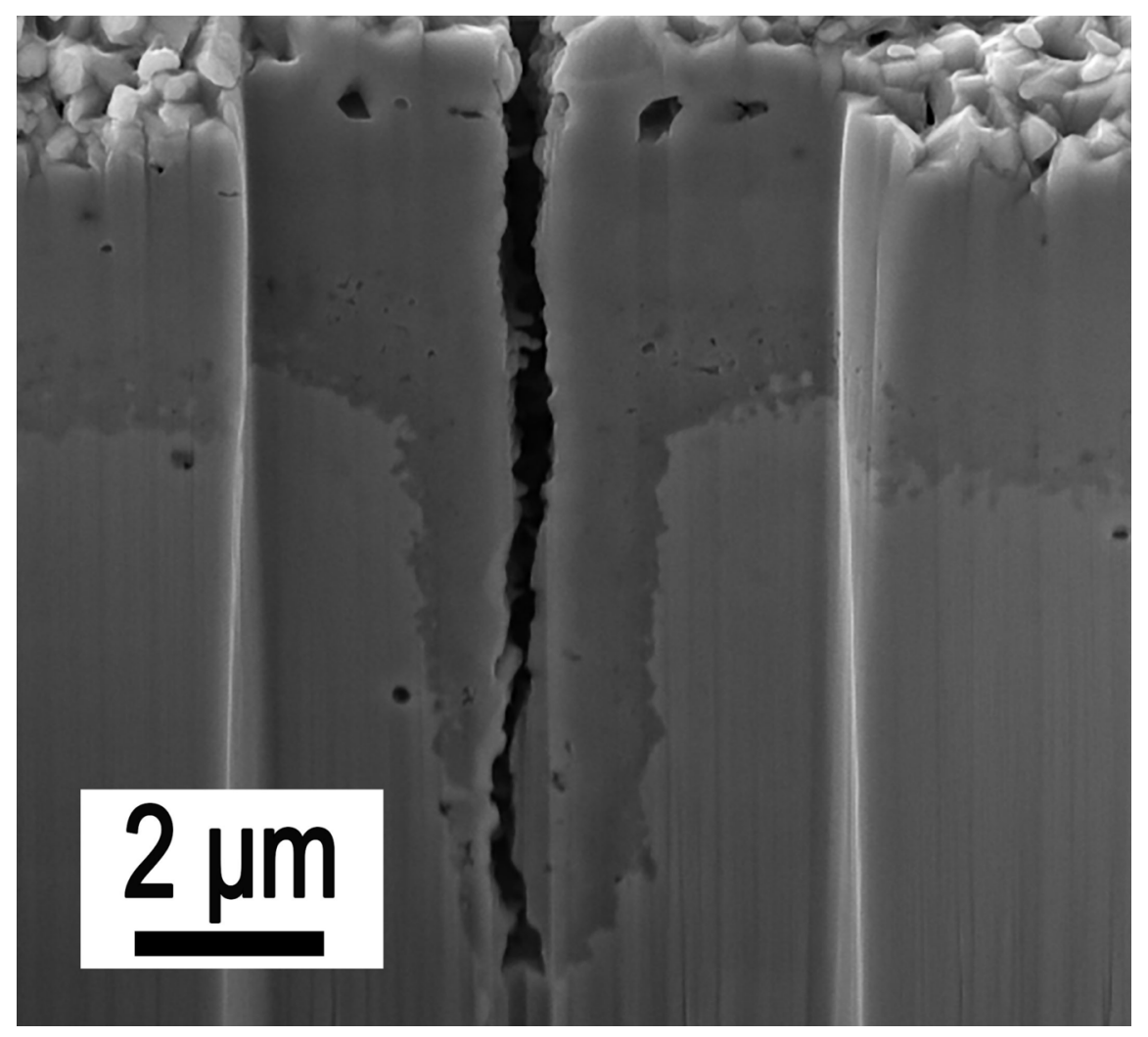

(a) (b)

Fig. 14. FIB cuts perpendicular to the surface and to the stress axis in a specimen subjected to OPD-TMF cycling; (a) a crack starting in the thick oxide layer; (b) well developed oxidized crack propagating in the material volume.

Fatigue cracks initiated from the thick oxide layer enter into the material independent whether they are at the grain boundary or within the grain. Fig. 15 displays the image of such two secondary cracks developed at the end of the fatigue life from the uniform cracked oxide layer of the specimen subjected to OPD-TMF cycling with total strain amplitude $6 \times 10^{-3}$. Transgranular crack propagation is evident from the EBSD image (Fig. 15b). 

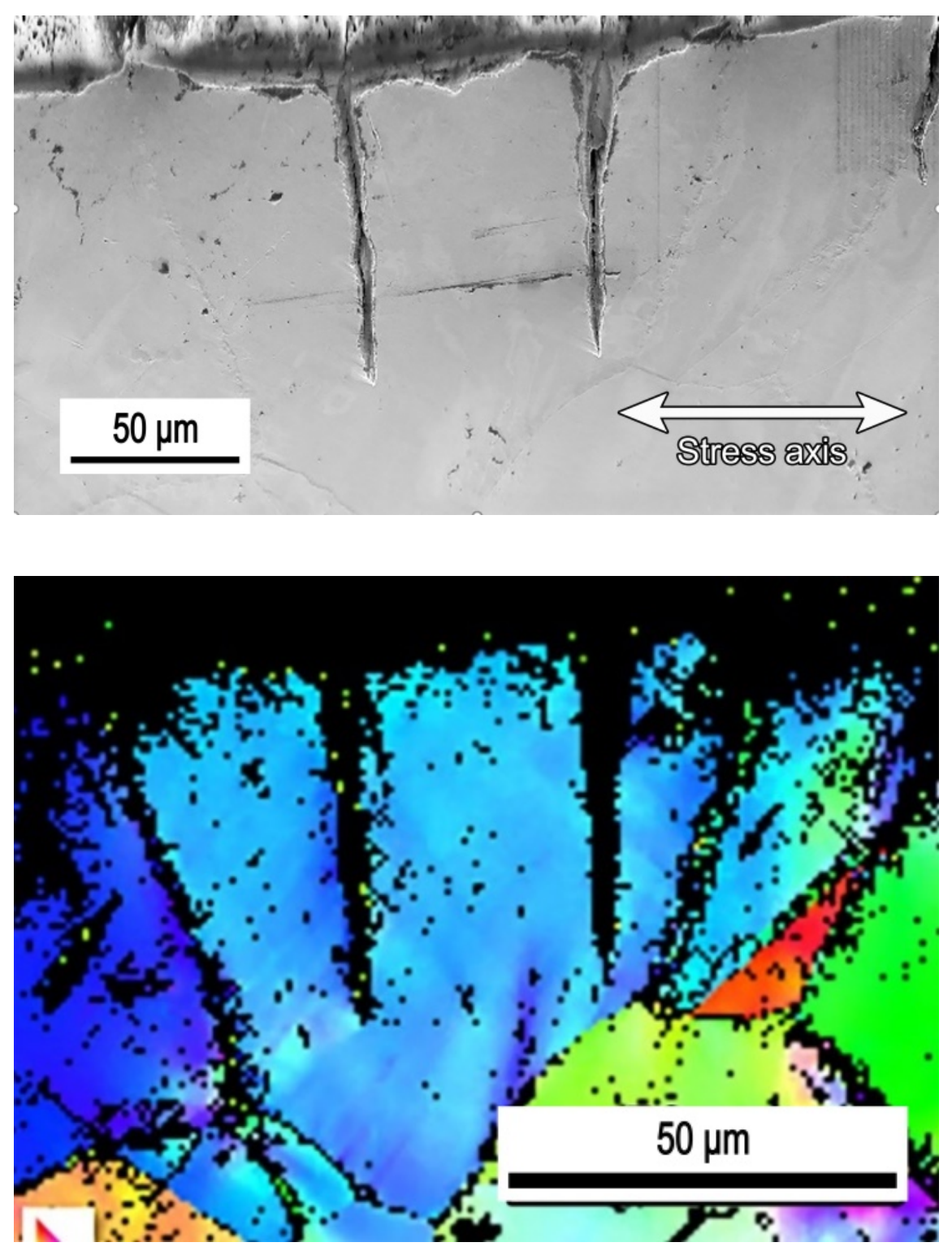

(a) (b)

Fig. 15. Longitudinal section of the specimen subjected to OPD-TMF cycling with total strain amplitude 6 $\times 10^{-3}$. Two transgranular cracks grow perpendicular to the loading axis; (a) SEM image, (b) EBSD image.

\section{Discussion}

\subsection{Mechanical response}

The effect of dwells on the cyclic stress-strain response in the thermomechanical cycling of Sanicro 25 steel can be best demonstrated by comparing the present results with previous results performed without the dwell. The change of the shape of the loop and the tendency of the change in the stress amplitude are illustrated by Fig. 1. The introduction of the dwell both in TMF-IPD and TMF-OPD cycling results in stress and also plastic strain relaxation at the highest temperature in a cycle and plastic strain amplitude thus increases. Moreover mean stress increases in OPD-TMF cycling and decreases in IPD-TMF cycling ${ }^{25}$, while it was approximately zero in cycling without dwells. 
The effect of the dwells on the cyclic hardening/softening curves is apparent from the plot of the stress amplitude vs. the number of cycles for cycling with dwells and without in Fig. 16 for total strain amplitude $6 \times 10^{-3}$. Introduction of dwell always leads to more rapid cyclic hardening; however, the peak stress amplitude during the test is smaller than in constant strain rate cycling. Pronounced saturation is found in TMF-OPD cycling. Both in IP-TMF cycling and in IPD-TMF cycling, the early initiation and growth of the crack prevent stress amplitude saturation since specimens are fractured. Therefore the stress amplitudes in halflife which are used for the construction of the cyclic stress-strain curves in IP-TMF and IPD-TMF cycling are much lower than in OP-TMF and OPD TMF cycling. The cyclic stress-strain curves are shown in Fig. 3 . The introduction of the dwell led to the decrease of the cyclic-stress strain curves but the drop is much more important in OPD-TMF than in IPD-TMF cycling. It is in agreement with lower dislocation density in specimens cycled with dwells in a cycle (Fig. 4). It also shows that the dislocation structure produced during the cycle is reduced more effectively in OPD-TMF cycle than in IPD-TMF cycle.

Introduction of the dwells results in the increase of the plastic strain amplitude in a cycle and in appreciable cycle asymmetry. In spite of negative mean stress built up in IPD-TMF cycling fatigue life decreases due to dwells in both types of cycling.

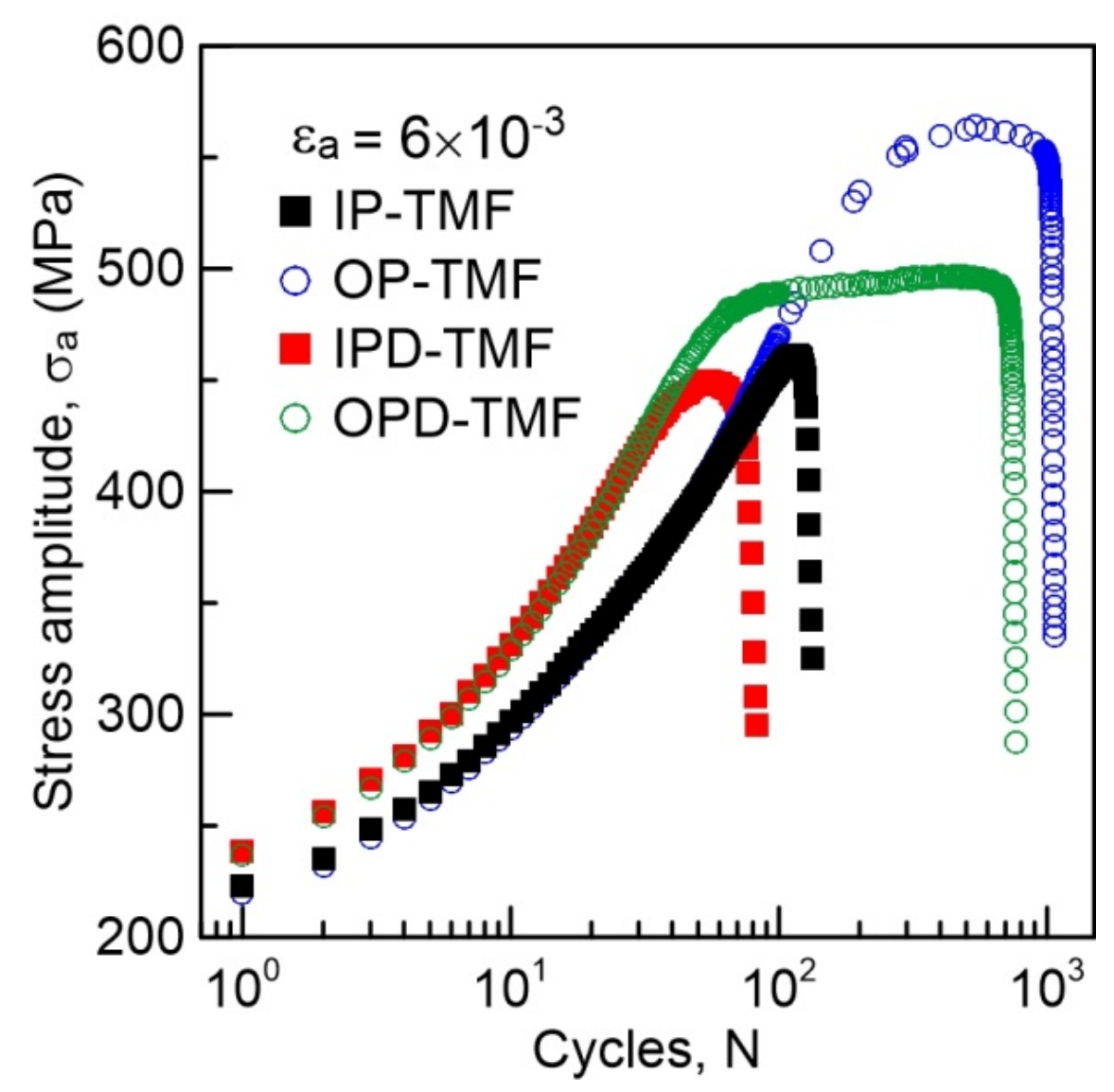

Fig. 16. Cyclic hardening/softening curves in TMF cycling with and without dwell for total strain amplitude $6 \times 10^{-3}$.

\subsection{Internal structure}

Investigation of the internal structure of the specimens subjected to TMF cycling with and without dwells revealed the important effect of the dwells on the dislocation substructure. Substructure in Fig. 4a and Fig. 
4b is very similar to the structure observed by Heczko et al. ${ }^{10}$ after constant strain rate high temperature cycling of Sanicro 25. High dislocation density and dislocations arranged in bands parallel to the primary slip plane are typical for IP-TMF cycling (Fig. 4a). It is apparent that the dominant effect in the formation of the dislocation structure has the part of the cycle when the specimen is deformed at high temperature. In specimens cycled in OP-TMF cycle, the density of bands is lower and the areas between the bands are filled with a homogeneous distribution of dislocations.

Dislocation structure in IPD-TMF and OPD-TMF cycled specimens differ substantially from the previous ones. 10 min dwell at $700{ }^{\circ} \mathrm{C}$ in a cycle has an important effect on the dislocation distribution. Dislocations produced in the cycle have enough time during $10 \mathrm{~min}$ relaxation at high temperature to be rearranged and even to disappear due to climb processes. Dislocations are not any more arranged in bands but individual segments are randomly arranged. High densities of precipitates which often pin dislocations are the characteristic feature of the internal structure. The role of small precipitates is important as obstacles for dislocation motion. The dislocation density in specimens subjected to OPD-TMF testing is even lower than in specimens subjected to IPD-TMF testing. This finding encourages the hypothesis that high temperature fatigue resistance of Sanicro 25 can be ascribed preferably to the dense distribution of precipitates produced during cyclic loading than to the high dislocation density.

A considerable number of different precipitates were found in specimens subjected to IPD-TMF and OPDTMF cycling. This corresponds to the finding ${ }^{29}$ that the density and in some cases also the size of the particles got larger with increasing time and temperature. Laves phases were also found in the microstructural study of the specimens Sanicro 25 exposed to $700{ }^{\circ} \mathrm{C}$ for 3000 hours reported by Chai et al. ${ }^{2}$. Warner et al. ${ }^{27}$ investigated thermomechanical behaviour of virgin and pre-aged specimens subjected to IP-TMF loading in the temperature range from $100{ }^{\circ} \mathrm{C}$ to $800{ }^{\circ} \mathrm{C}$. Microstructural investigation revealed the formation of $\mathrm{Nb}(\mathrm{C}, \mathrm{N})$, Z-phase, $\mathrm{Cr}_{2} \mathrm{~N}, \mathrm{M}_{23} \mathrm{C}_{6}$ and $\mu$-phase in virgin specimens while strained pre-aged specimens resulted in the extra formation of Laves phase $(\mathrm{Fe}, \mathrm{Cr})_{2} \mathrm{~W}$. Precipitates having larger dimensions and lower density like tungsten carbides or Z-phase do not affect substantially the material strength. The small precipitates containing copper or niobium which precipitate during cycling ${ }^{11}$ and very effectively also during dwell periods are supposed to be mostly responsible for the high cyclic stress-strain response of the material. $\mathrm{M}_{23} \mathrm{C}_{6}$ particles which nucleate at high angle grain boundaries do not affect the stress-strain response but have an important effect on the depletion of grain boundaries by chromium and their preferential oxidation (see 4.3).

Recently Li et al. ${ }^{30}$ measured strain rate dependence of the cyclic plastic stress-strain response in Sanicro 25 steel and explained it in terms of the different distributions of $\mathrm{M}_{23} \mathrm{C}_{6}$ precipitates. Present results point to the appearance of the $\mathrm{M}_{23} \mathrm{C}_{6}$ precipitates preferentially at the grain boundaries and to the homogeneous distribution of fine $\mathrm{Cu}$ - and Nb-rich nanoprecipitates which determine the high cyclic stress of the material.

\subsection{Damage mechanism and fatigue life.}

Mechanisms of fatigue crack initiation in Sanicro 25 at ambient temperature and at elevated temperature differ substantially. While straining at room temperature, the principal role is played by the localization of the cyclic plastic strain and formation of extrusions and intrusions within the grains ${ }^{13,31}$. In high temperature cycling the oxidation, namely the oxidation of the grain boundaries is a dominant damage mechanism ${ }^{8,14}$. It is similar to high temperature fatigue with dwells in high-strength superalloys ${ }^{32}$. Formation of $\mathrm{Cr}$ rich carbides $\mathrm{M}_{23} \mathrm{C}_{6}$ at grain boundaries leads to the depletion of the neighbour matrix from $\mathrm{Cr}$ and easy oxidation in high temperature environment. The same is true for thermomechanical cycling since high temperature in a cycle leads to grain boundary oxidation ${ }^{20}$. Different mechanisms of crack initiation were found in IP-TMF and OP-TMF cycling. The introduction of the dwell periods at maximum temperature in IP-TMF cycle substantially increases the oxidation and moreover it can launch the internal damage in the form of internal cracks.

Li et al. ${ }^{24}$ studied damage mechanisms in austenitic steel X2CrNiMo18.12 subjected to in-phase thermomechanical fatigue in the lower temperature range, namely $250{ }^{\circ} \mathrm{C}$ to $450{ }^{\circ} \mathrm{C}$. They found localization of the 
cyclic plastic strain in PSBs and formation of PSMs on the surface of the material. Both grain boundaries and PSMs were more vulnerable to oxidation under thermo-mechanical fatigue loadings and thus were preferentially oxidized and fatigue cracks started from these locations. In the case of thermomechanical fatigue in the temperature range $250{ }^{\circ} \mathrm{C}$ to $700{ }^{\circ} \mathrm{C}$ studied here PSBs and surface PSMs do not play a significant role in the evolution of the damage and either grain boundaries in IP-TMF cycling or parallel cracks in a thick oxide layer in OP-TMF cycling are responsible for fatigue crack initiation.

Dwell periods in TMF cycle do not change the damage mechanisms radically. In IPD-TMF cycling the grain boundaries play the most significant role. Grain boundaries become oxidized more intensively than the rest of the surface and oxide extrusions and oxide intrusions are intensively produced. Preferentially in grain boundaries perpendicular to the loading axis, the oxide is cracked in tensile half-cycle. Oxygen is admitted to the tip of the crack and local oxidation of the crack tip and repeated cracking of the produced oxide during tensile loading leads to the early crack growth. Dwell time periods at maximum temperature enhance significantly the local oxidation of the crack tip neighbourhood since the crack in IPD-TMF cycle is open. The crack growth rate therefore increases and fatigue life of specimens subjected to IPD-TMF loading decreases.

In OPD-TMF cycling the preferential oxidation of the grain boundaries is suppressed since at high temperature the specimen is in compression. Thick oxide layer develops on the whole surface of the specimen. As soon as the thickness of the oxide exceeds a certain quantity in the surface layer several cracks perpendicular to the stress axis arise. Many surface cracks remain open even in maximum compression at high temperature (see Fig. 13) and this allows admitting of the oxidising atmosphere to the metal. Local oxidation (see Fig. 14) and subsequent cracking of the oxide lead to the crack growth, this time transgranularly, perpendicular to the loading axis. The growth rate of these cracks is substantially smaller than in IPD-TMF cycling and thus the fatigue life is longer. Nevertheless, the introduction of the dwell period in maximum compression at high temperature enhances oxidation and in comparison with OP-TMF cycling, the fatigue life decreases.

Different damage mechanisms and enhancement of the damage due to longer oxidation during the dwells is reflected in the fatigue life of tested specimens. Fig. 17 shows the Manson-Coffin law for specimens subjected to TMF cycling with dwells and without dwells. It is apparent that in the case of IPD-TMF cycling the fatigue life slightly decreases possibly due to the increased plastic strain amplitude as a result of the dwell. Long oxidation time at high temperature and participation of the internal damage are the main factors contributing to the decrease of the fatigue life. OPD-TMF cycling with the total strain amplitudes higher than in OP-TMF cycling led to the substantial decrease of the fatigue life (see Fig. 17 where all points are shifted to lower fatigue lives). However, plastic strain amplitude due to the dwell increased substantially and all data of OPD-TMF cycling in Fig. 17 are also shifted to higher plastic strain amplitudes. As a result, both sets of data (OP-TMF and OPD-TMF) can be also approximated by a single Manson-Coffin law. 


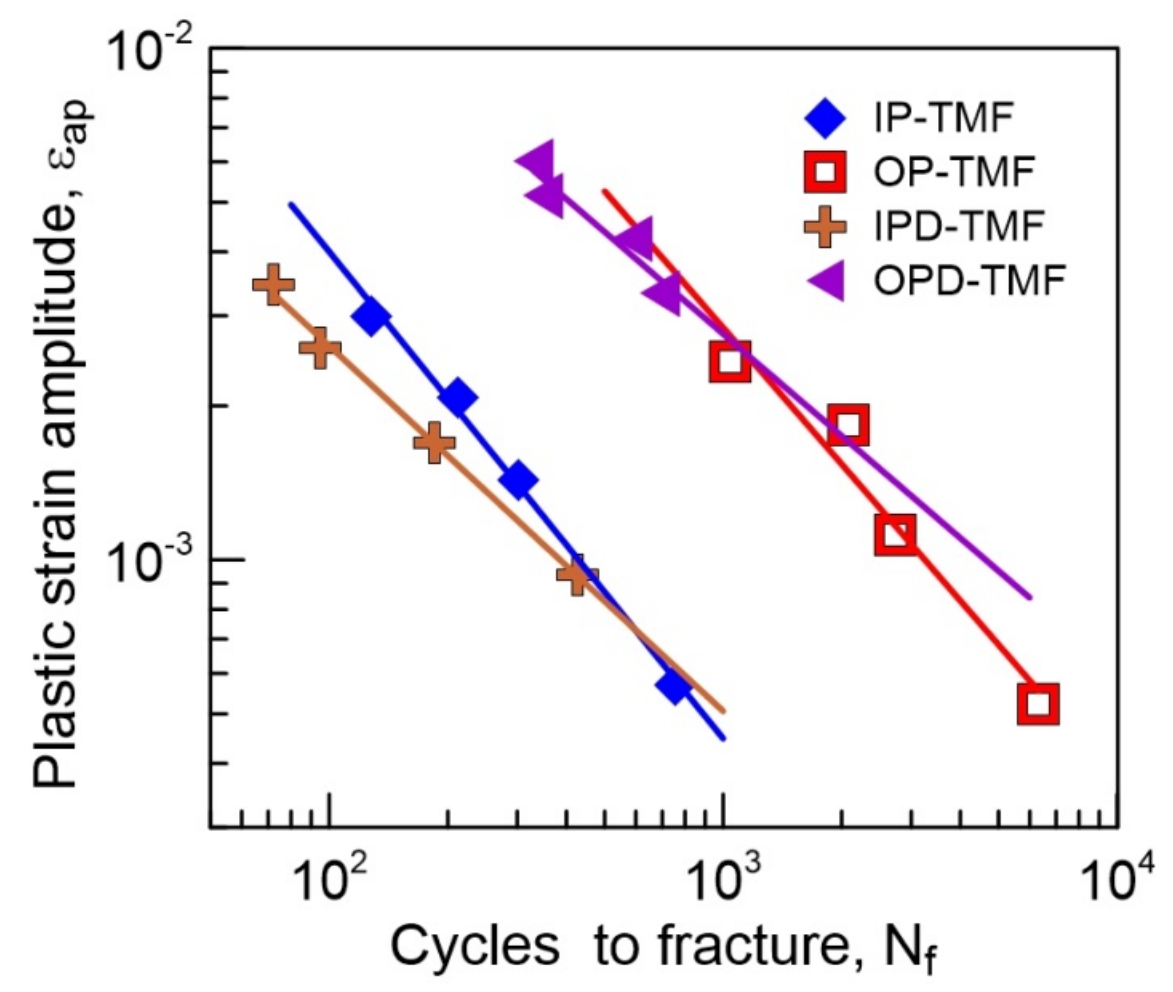

Fig. 17. Manson-Coffin plots for specimens subjected to TMF cycling with dwells and without dwells.

The analysis of the fatigue lives in thermomechanical fatigue cycling with dwells indicates that plastic strain amplitude is not the only quantity deciding the fatigue life since time factor plays also an important role. It is expected that still longer dwell times in a cycle would increase fatigue damage further and contribute to the reduction of the fatigue life.

\section{Conclusions}

Study of the effect of the dwells at maximum temperature in thermomechanical out-of-phase fatigue and the comparison with in-phase fatigue and thermomechanical fatigue without dwells of superaustenitic Sanicro 25 steel led to the following conclusions:

1. Cyclic stress-strain response is substantially affected by dwells leading to more rapid initial hardening both in OPD-TMF and in IPD-TMF cycling. In OPF-TMF cycling due to the extension of the fatigue life long period of stress amplitude saturation was found. Introduction of dwells results in the shift of cyclic stress-strain curves to lower stress amplitudes.

2. Internal dislocation structure after cycling with dwells changes markedly in comparison with cycling without dwells. Random distribution of dislocation segments without any arrangement in bands parallel to the crystallographic directions was found. Dislocations are often pinned by nanoparticles. Dislocation density is lower in the case of OPD-TMF cycling than in the case of IPD-TMF cycling.

3. The introduction of dwells led to the increase of the nanoparticle density. In addition to $\mathrm{Cu}$-rich and Nb-rich particles larger W-rich particles were identified. Systematic formation of $\mathrm{Cr}$ rich $\mathrm{M}_{23} \mathrm{C}_{6}$ carbide on the grain boundaries was found.

4. Surface fatigue crack in IPD-TMF cycling starts in the oxidized grain boundaries and continues intergranularly. Its growth is accelerated by the formation of internal cracks which join the principal crack during its growth. 
5. In OPD-TMF cycling the crack initiation on the grain boundaries is suppressed. The thick oxide layer is formed and when its thickness reaches critical depth, parallel open cracks perpendicular to the stress axis arise. The oxygen has locally access to the metal and localized oxidation and oxide cracking leads to early crack growth. Fatigue cracks grow transgranularly.

\section{Acknowledgements}

The equipment used in the present project was provided by the Large Infrastructures for Research, Experimental Development and Innovation - project IPMinfra, LM2015069. The support by the project CEITEC 2020 (LQ1601) of the Ministry of Education, Youth and Sports of the Czech Republic, by project RVO 6808173 of the Academy of Sciences and by grant 18-03615S of the Czech Grant Agency, Czechia is gratefully acknowledged.

\section{References}

1. Wheeldon JM, Shingledecker JP (2013) Materials for boilers operating under supercritical steam conditions. Ultra-Supercritical Coal Power Plants: Materials, Technologies and Optimisation. Optimisation, 81-103.

2. Chai G, Bostrom M, Olaison M, Forsberg U (2013) Creep and LCF Behaviors of Newly Developed Advanced Heat Resistant Austenitic Stainless Steel for A-USC. Procedia Engineer . 55 : 232-239.

3. Sandvikwww.materials.sandvik/en/products/tube-pipe-fittings-and-flanges/high-performancematerials/high-temperature-stainless-steels/sanicro-25/.

4. Sun F, Gu YF, Yan JB, Zhong ZH, Yuyama M (2016) Phenomenological and microstructural analysis of intermediate temperatures creep in a Ni-Fe-based alloy for advanced ultra-supercritical fossil power plants.Acta Mater . 102 : 70-78.

5. Kloc L, Dymáček P, Sklenička V (2018) High temperature creep of Sanicro 25 austenitic steel at low stresses. Mat Sci Eng a-Struct. 722 : 88-92.

6. Zhang Y, Jing H, Xu L, Zhao L, Han Y, Liang J (2017) Microstructure and texture study on an advanced heat-resistant alloy during creep. Mater Charact . 130 : 156-172.

7. Zhao L, Song K, Zhang Y, et al. (2019) Creep Rupture Assessment of New Heat-Resistant Sanicro 25 Steel Using Different Life Prediction Approaches. J Mater Eng Perform . 28 : 7464-7474.

8. Polák J, Petráš R, Heczko M, Kuběna I, Kruml T, Chai G (2014) Low cycle fatigue behavior of Sanicro25 steel at room and at elevated temperature. Materials Science and Engineering A . 615 : 175-182.

9. Polák J, Petráš R, Heczko M, Kruml T, Chai G (2016) Evolution of the cyclic plastic response of Sanicro 25 steel cycled at ambient and elevated temperatures. Int $J$ Fatigue . 83 : 75-83.

10. Heczko M, Polák J, Kruml T (2017) Microstructure and dislocation arrangements in Sanicro 25 steel fatigued at ambient and elevated temperatures. Mat Sci Eng a-Struc . 680 : 168-181.

11. Heczko M, Esser BD, Smith TM, et al. (2018) Atomic resolution characterization of strengthening nanoparticles in a new high-temperature-capable $43 \mathrm{Fe}-25 \mathrm{Ni}-22.5 \mathrm{Cr}$ austenitic stainless steel.Mat Sci Eng a-Struct . 719 : 49-60.

12. Zhang Y, Jing HY, Xu LY, Zhao L, Han YD, Zhao YX (2017) High-temperature deformation and fracture mechanisms of an advanced heat resistant Fe-Cr-Ni alloy. Mat Sci Eng a-Struct . 686 : 102-112.

13. Mazánová V, Polák J (2018) Initiation and growth of short fatigue cracks in austenitic Sanicro 25 steel. Fatigue Fract Eng $M .41$ : 1529-1545.

14. Mazánová V, Heczko M, Polák J (2018) Fatigue crack initiation and growth in 43Fe-25Ni-22.5Cr austenitic steel at a temperature of 700 degrees C. Int J Fatigue . 114 : 11-21. 
15. Li BB, Zheng YM, Shi SW, Chen X (2019) Microcrack nucleation and early crack growth of a nuclear grade nitrogen alloyed austenitic stainless steel X2CrNiMo18.12 under thermomechanical fatigue loading.Int J Pres Ves Pip . 172 : 188-198.

16. Li HZ, Jing HY, Xu LY, et al. (2019) Cyclic damage behavior of Sanicro 25 alloy at 700 degrees C: Dispersed damage and concentrated damage. International Journal of Plasticity . 116 : 91-117.

17. Li HZ, Jing HY, Xu LY, et al. (2019) Fatigue behavior, microstructural evolution, and fatigue life model based on dislocation annihilation of an $\mathrm{Fe}-\mathrm{Ni}-\mathrm{Cr}$ alloy at 700 degrees C. International Journal of Plasticity . $118: 105-129$.

18. Li HB, Jing H, Xu L, et al. (2019) Life, dislocation evolution, and fracture mechanism of a 41Fe-25.5Ni$23.5 \mathrm{Cr}$ alloy during low cycle fatigue at $700^{\circ} \mathrm{C}$. Int $J$ Fatigue . 119 : 20-33.

19. Li HZ, Jing HY, Xu LY, et al. (2019) Cyclic deformation behavior of an Fe-Ni-Cr evolution and cyclic hardening model alloy at 700 degrees C: microstructural evolution and cyclic hardening model. Mat Sci Eng a-Struct . $744:$ : 94-111.

20. Petráš R, Škorík V, Polák J (2016) Thermomechanical fatigue and damage mechanisms in Sanicro 25 steel. Mat Sci Eng a-Struct .650 : 52-62.

21. Petráš R, Škorík V, Polák J (2016) Damage Evolution in Thermomechanical Loading of Stainless Steel. Procedia Struct Inte . 2 : 3407-3414.

22. Petráš R, Polák J (2018) Damage mechanism in austenitic steel during high temperature cyclic loading with dwells. Int $J$ Fatigue .113 : 335-344.

23. Warner H, Calmunger M, Chai G, et al. (2018) Fracture and Damage Behavior in an Advanced Heat Resistant Austenitic Stainless Steel During LCF, TMF and CF. Proc Struct Integrity . 13 : 843-848.

24. Li BB, Zheng YM, Shi SW, Liu YM, Li YJ, Chen X (2019) Microcrack initiation mechanisms of 316LN austenitic stainless steel under in-phase thermomechanical fatigue loading. Mat Sci Eng a-Struct .752 : 1-14.

25. Polák J, Petráš R (2020) Cyclic plastic response and damage mechanisms in superaustenitic steel Sanicro 25 in high temperature cycling - Effect of tensile dwells and thermomechanical cycling. Theor Appl Fract Mec. $108: 102641$.

26. Heczko M, Esser BD, Smith TM, et al. (2017) On the origin of extraordinary cyclic strengthening of the austenitic stainless steel Sanicro 25 during fatigue at 700 degrees C. Journal of Materials Research . 32 : 4342-4353.

27. Warner H, Calmunger M, Chai GC, Johansson S, Moverare J (2019) Thermomechanical fatigue behaviour of aged heat resistant austenitic alloys. Int J Fatigue . 127 : 509-521.

28. Zurek J, Yang SM, Lin DY, Huttel T, Singheiser L, Quadakkers WJ (2015) Microstructural stability and oxidation behavior of Sanicro 25 during long-term steam exposure in the temperature range 600-750 degrees C. Mater Corros . 66 : 315-327.

29. Sourmail T (2001) Precipitation in creep resistant austenitic stainless steels. Mater Sci Tech-Lond . 17 : $1-14$.

30. Li HZ, Jing HY, Xu LY, et al. (2020) Effect of strain rate induced M23C6 distribution on cyclic deformation behavior: Cyclic hardening model. International Journal of Plasticity . 127.

31. Polák J, Petráš R, Chai GC, Škorík V (2016) Surface profile evolution and fatigue crack initiation in Sanicro 25 steel at room temperature. Mat Sci Eng a-Struct . 658 : 221-228.

32. Krupp U, Wackermann K, Christ HJ, Colliander MH, Stiller K (2017) Intergranular Oxidation Effects During Dwell-Time Fatigue of High-Strength Superalloys. Oxid Met . 88 : 3-14. 


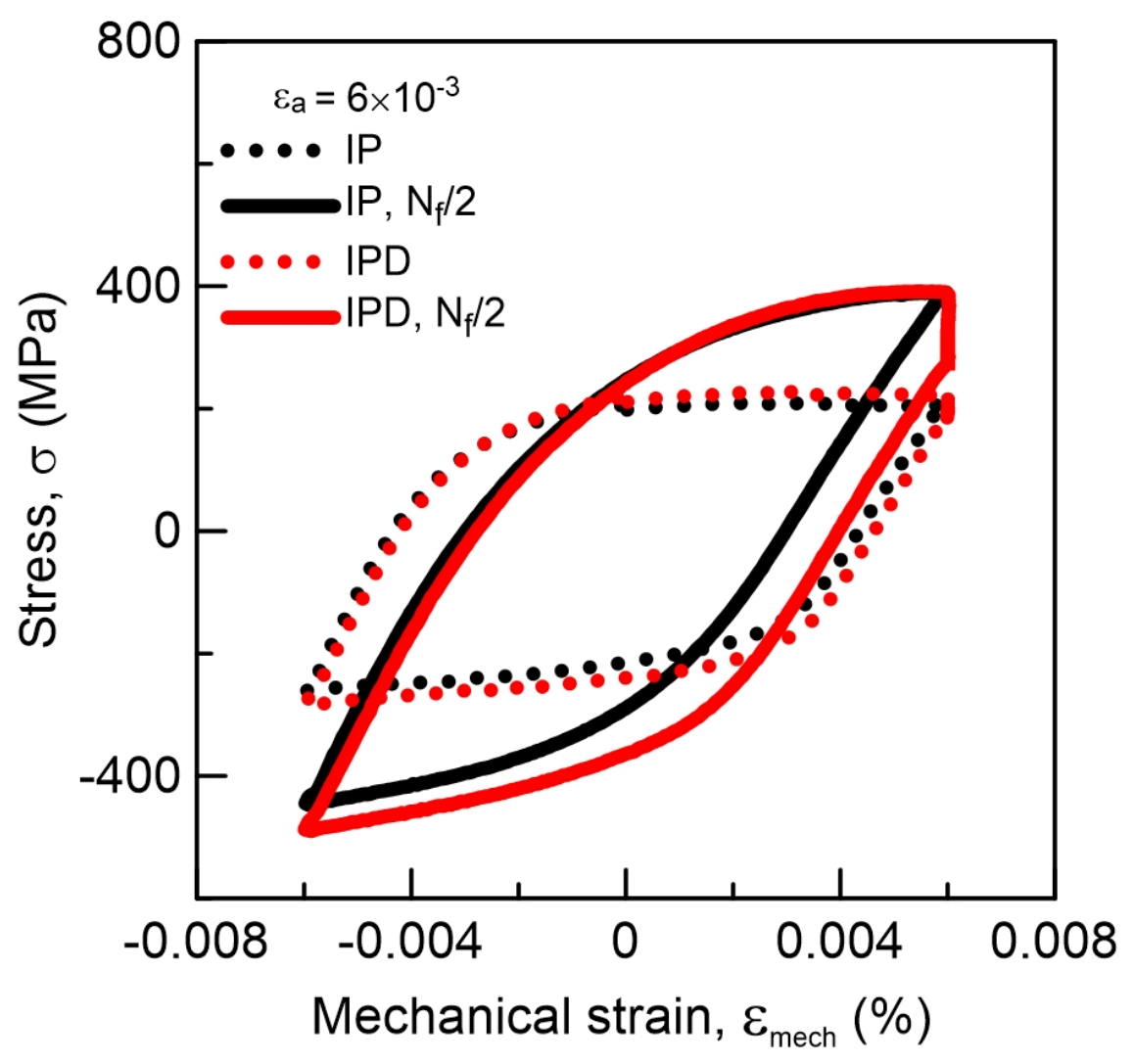




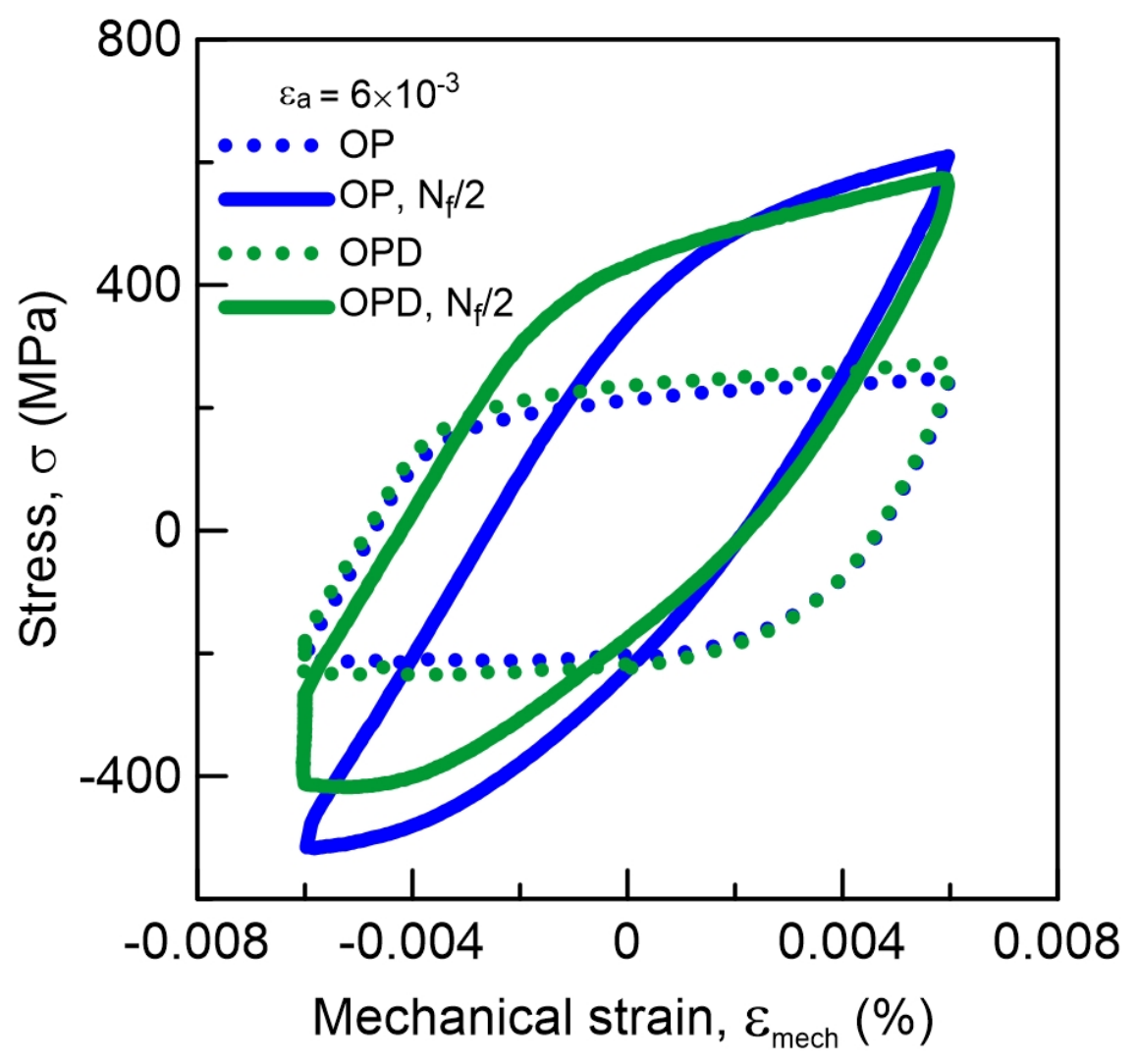




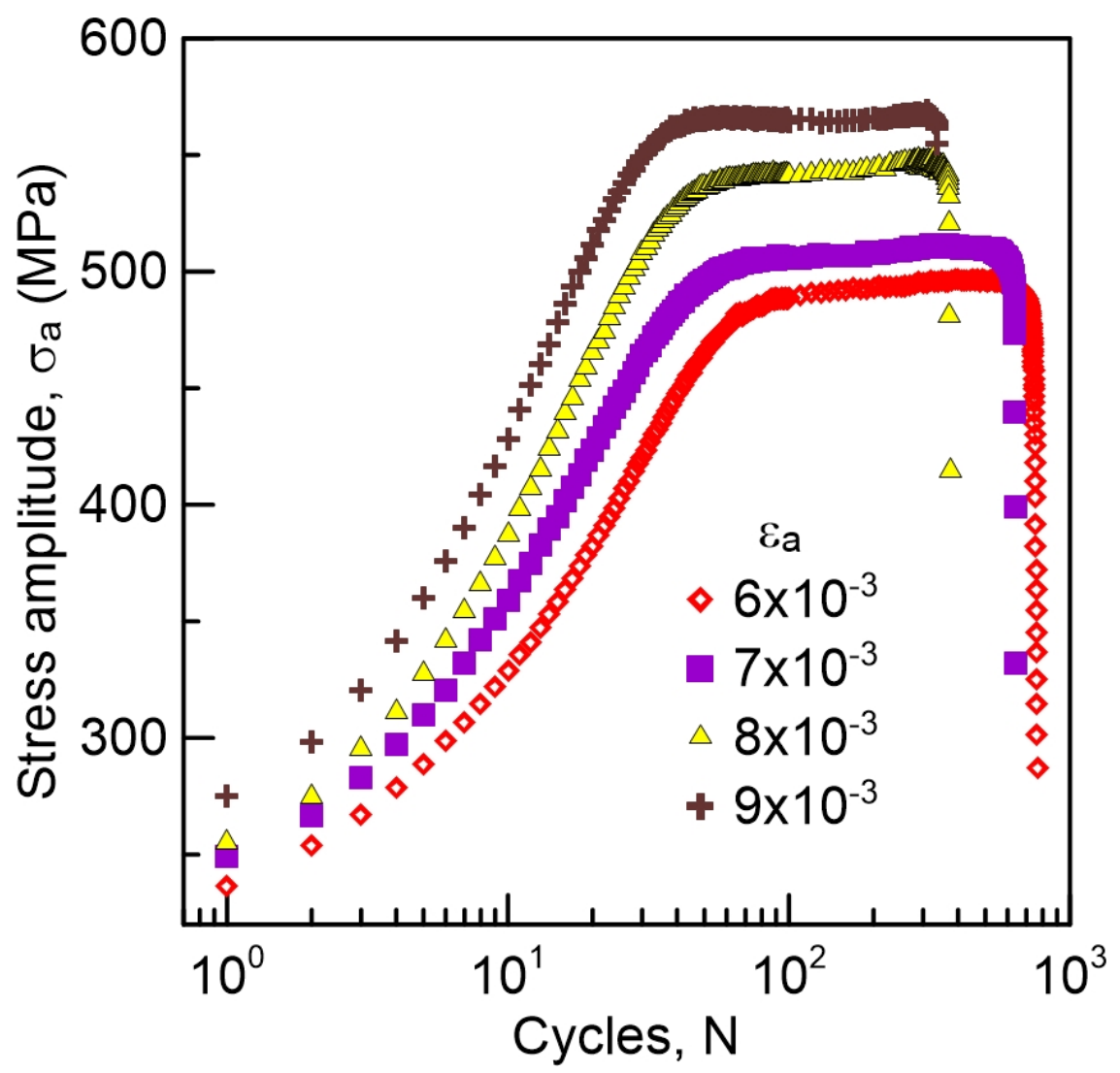




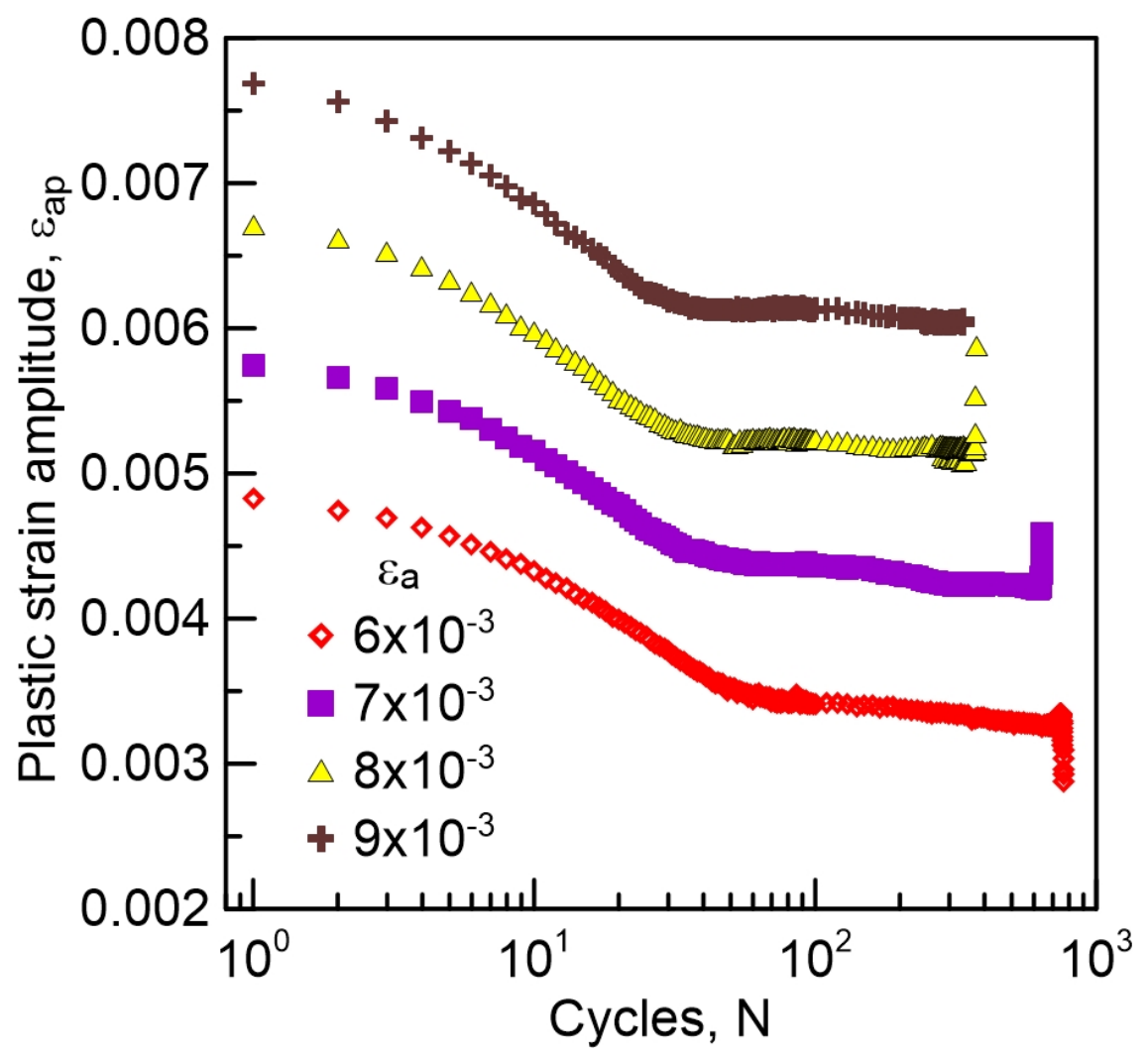



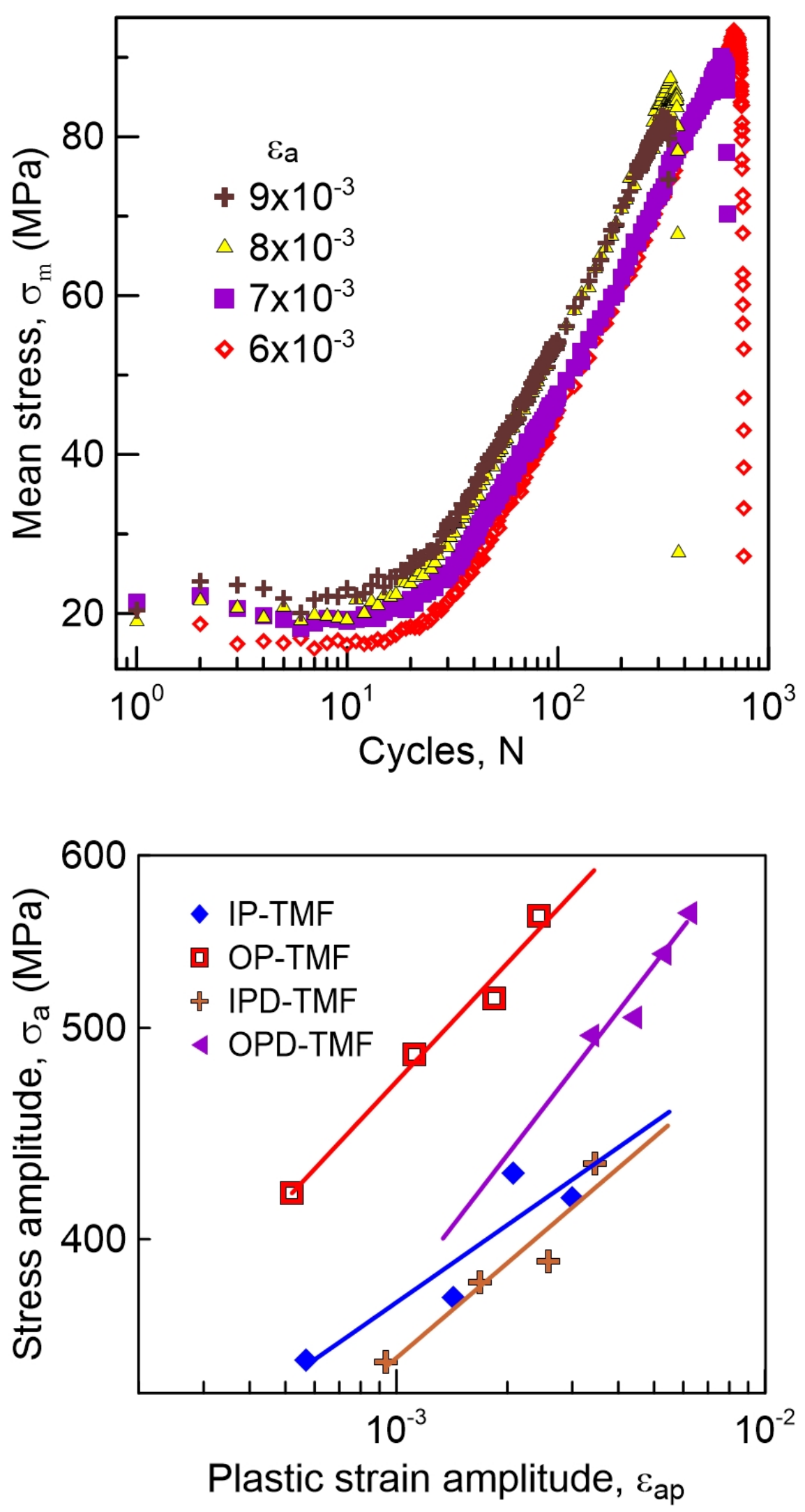


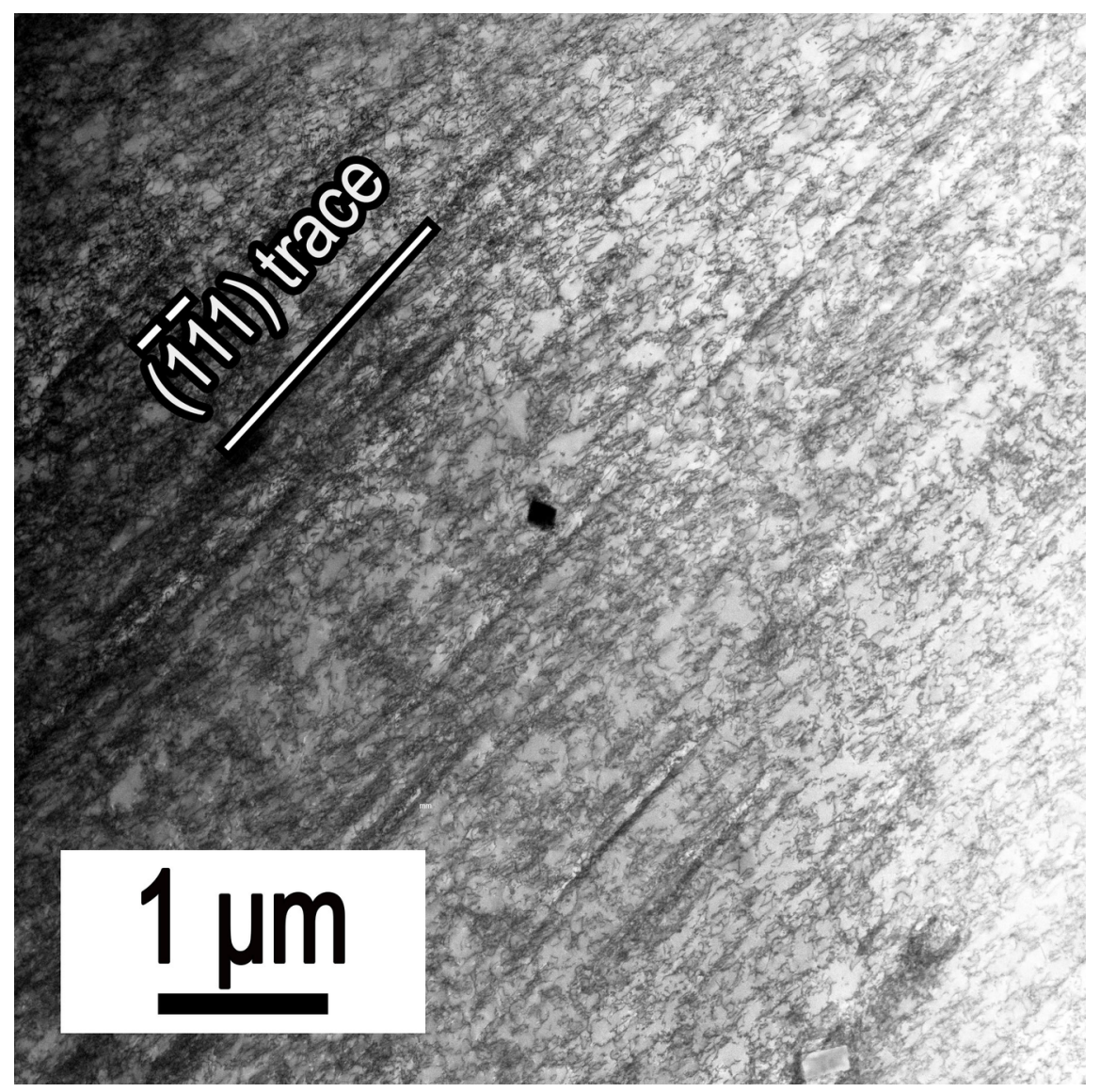




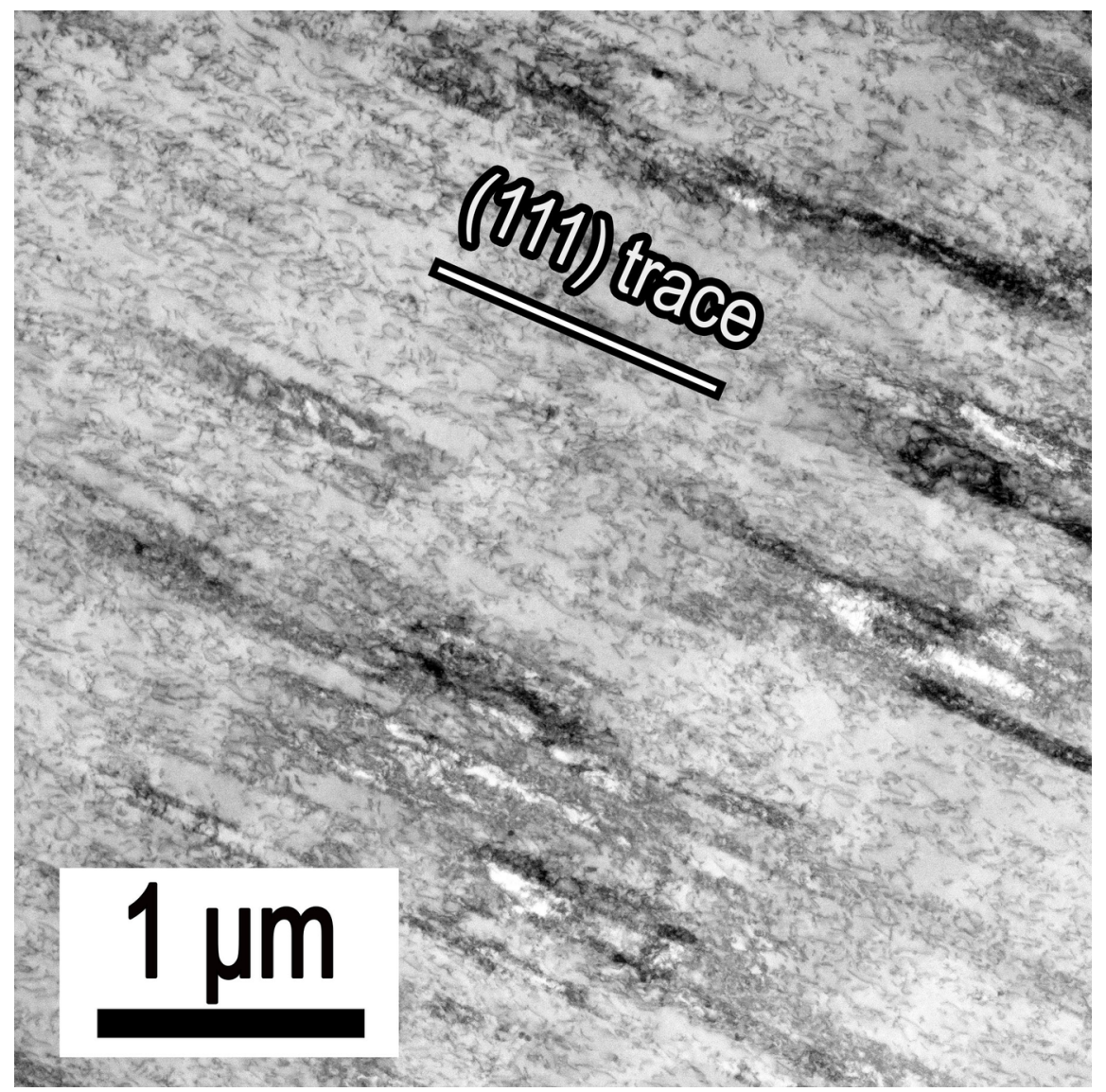




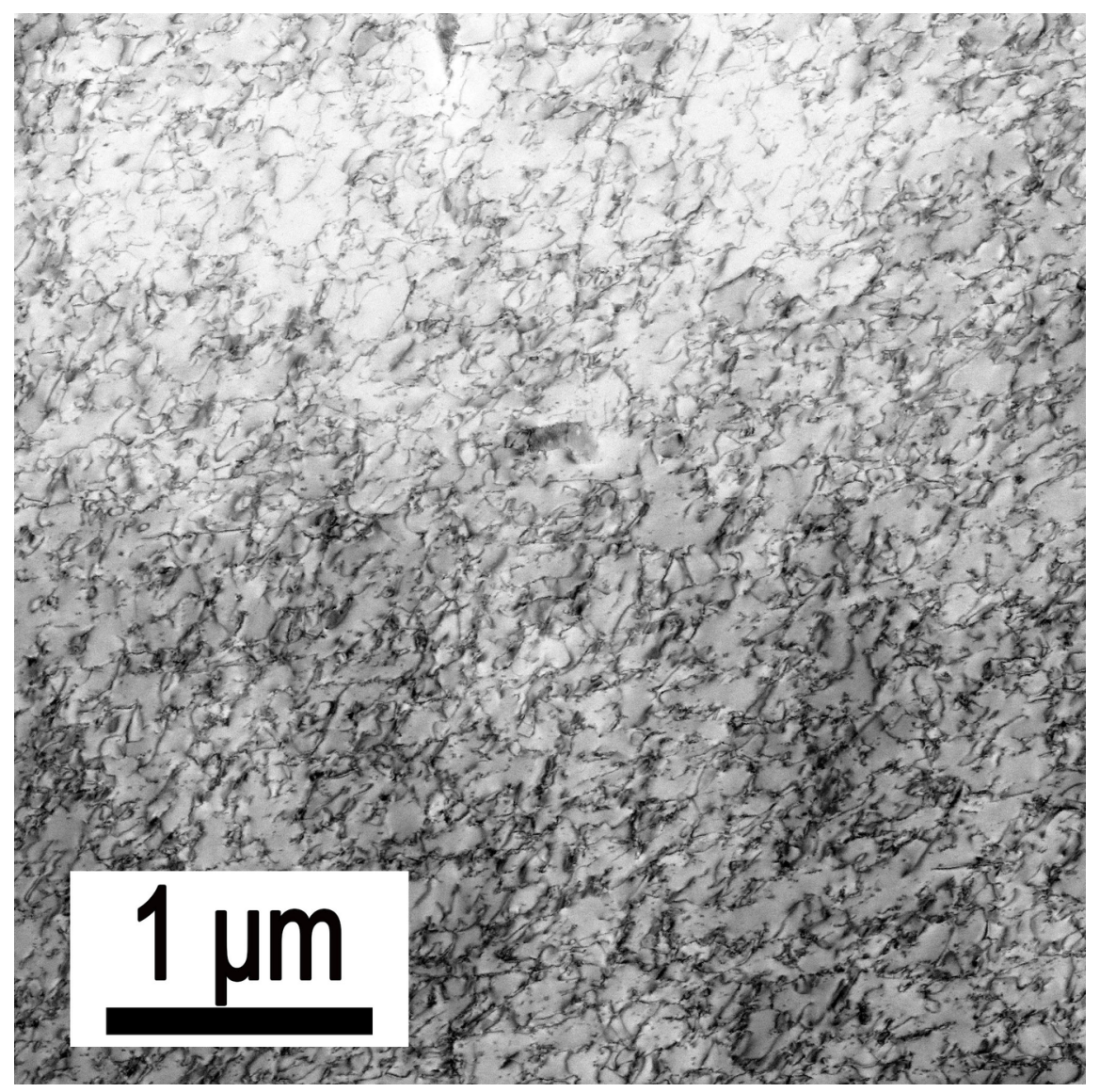



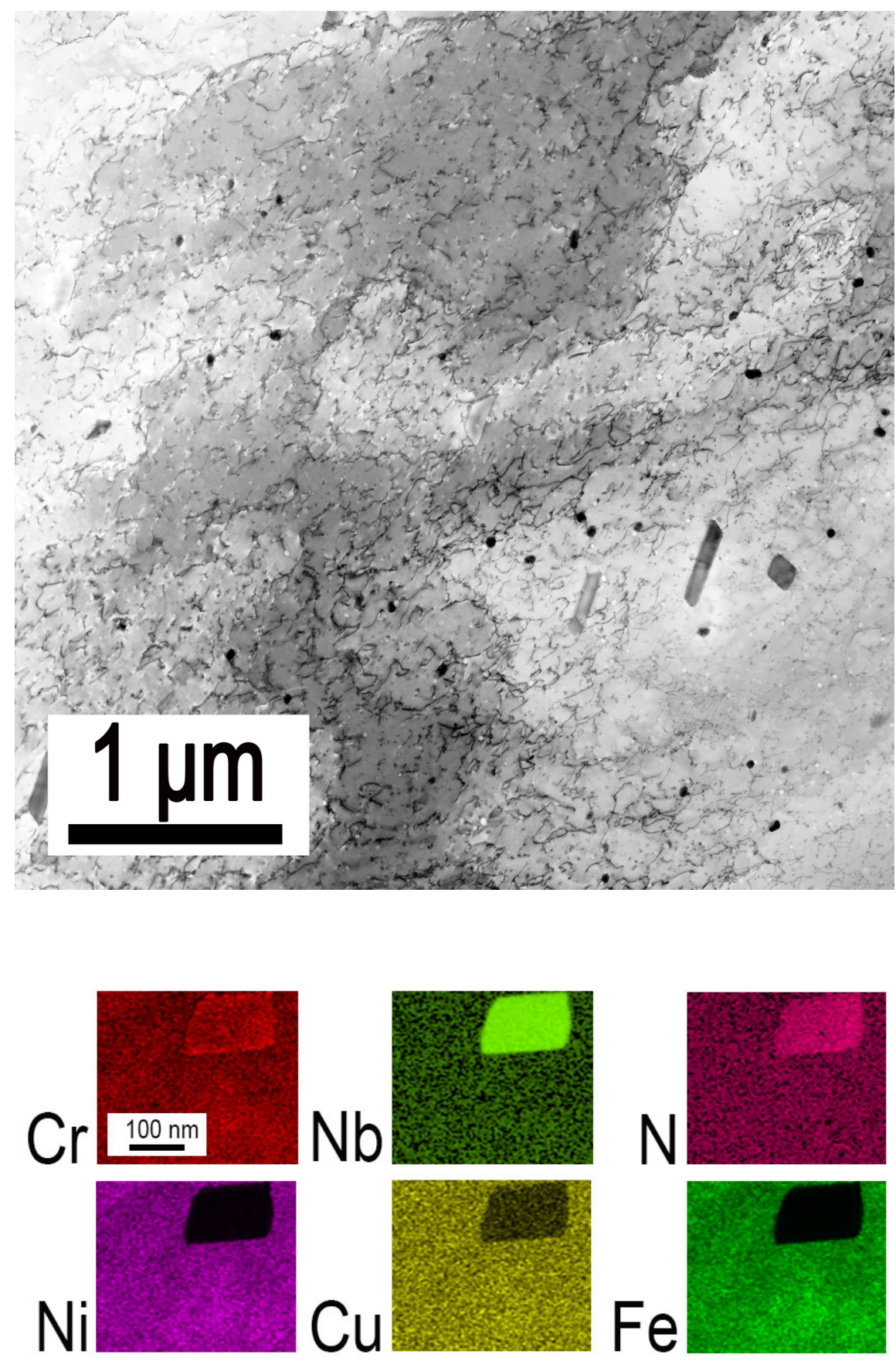

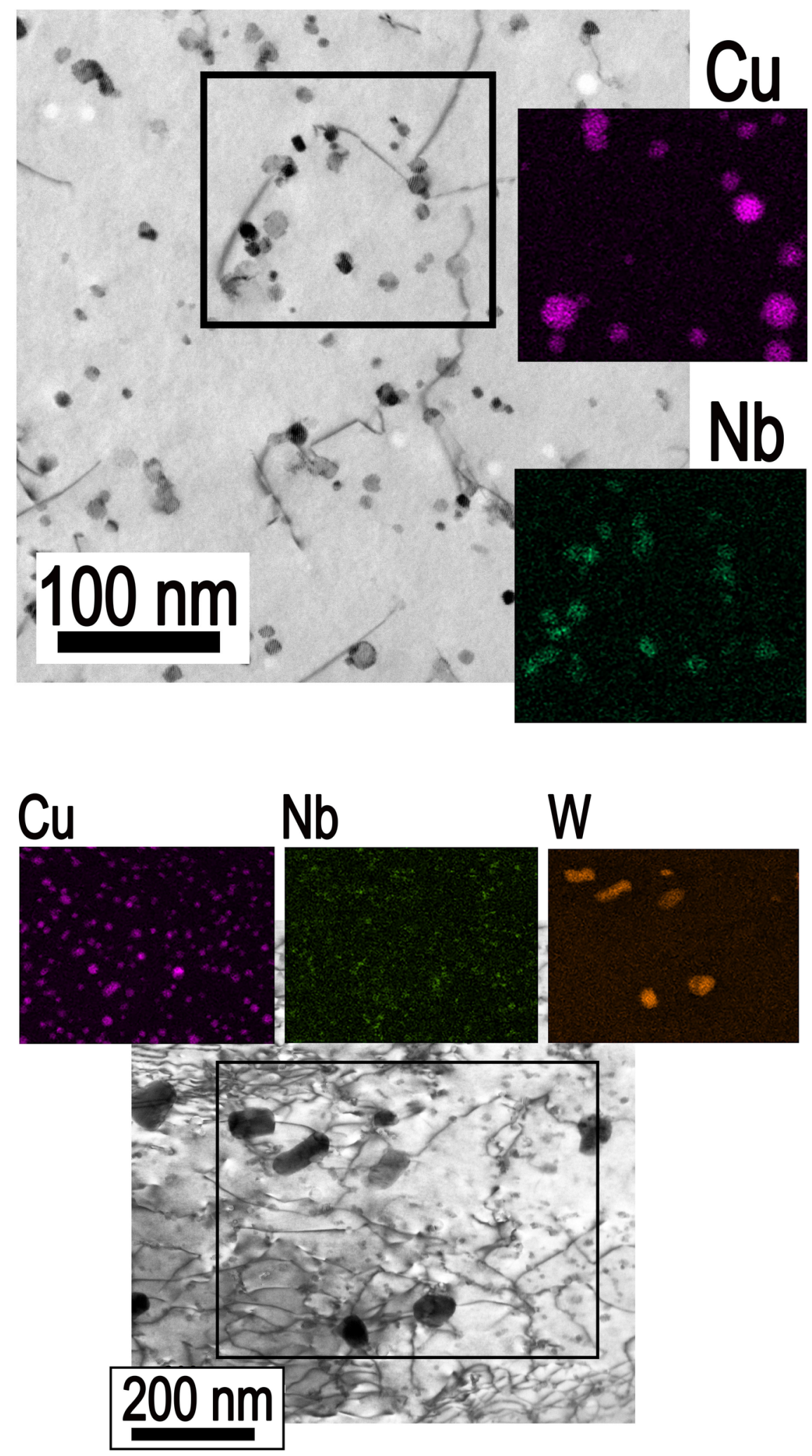

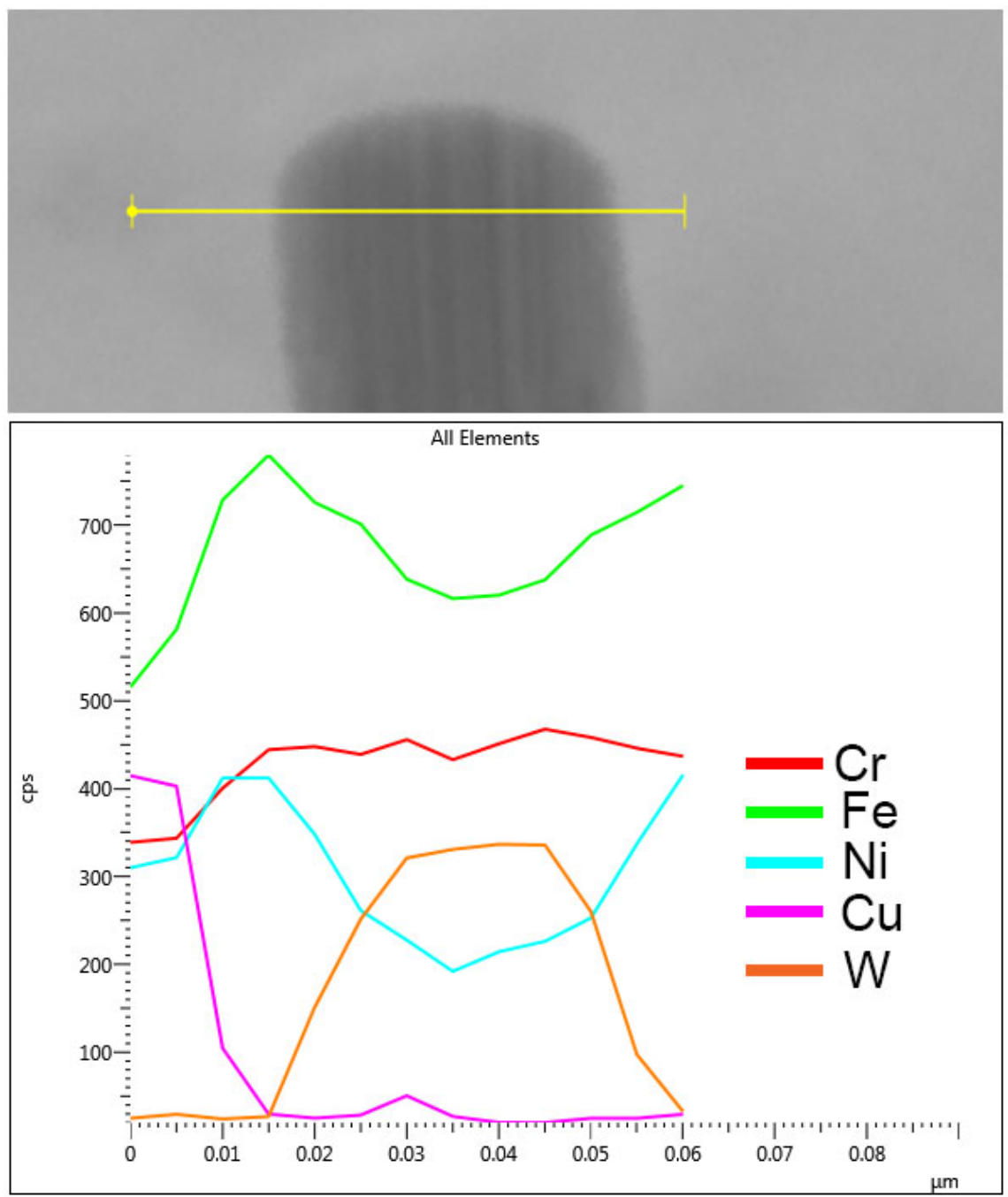

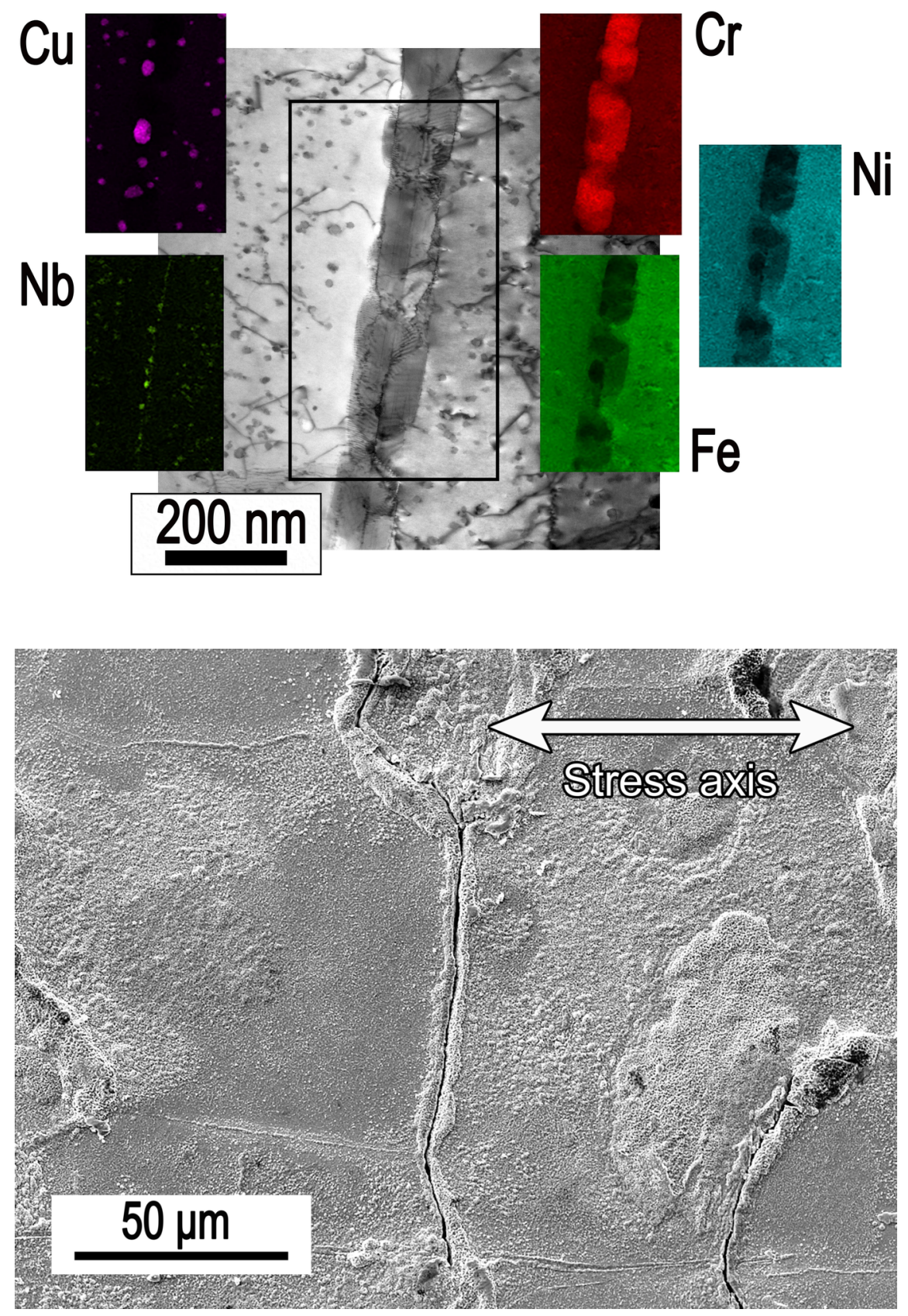


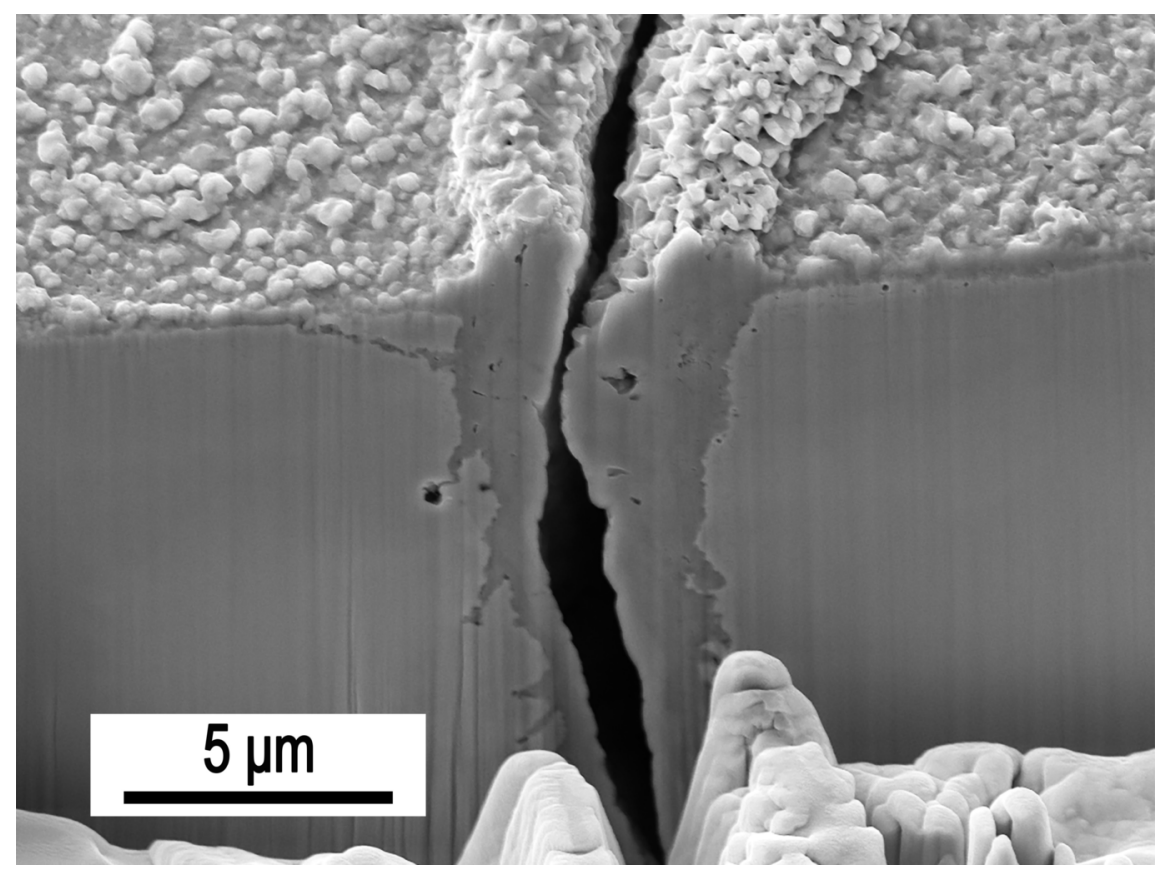




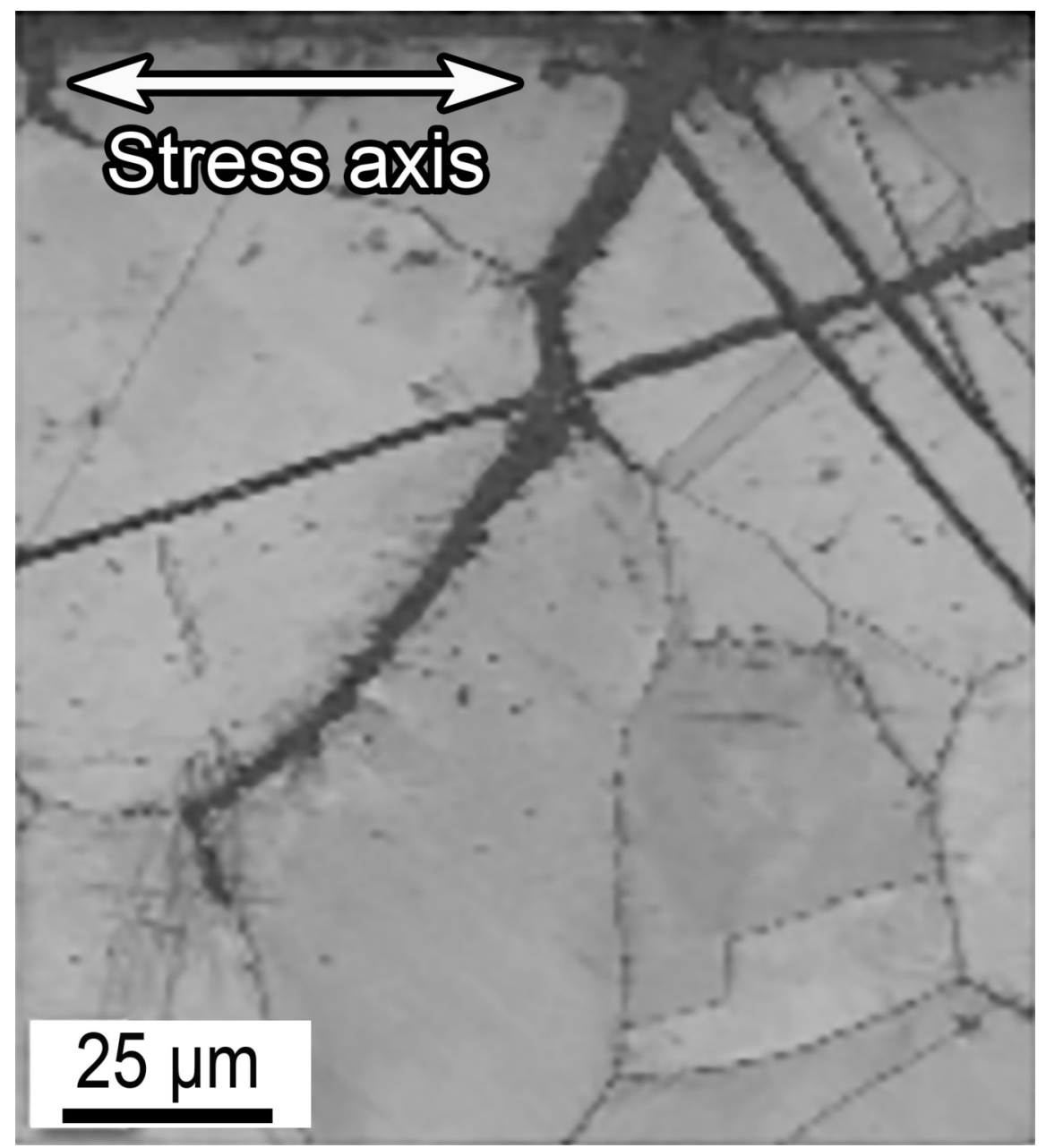




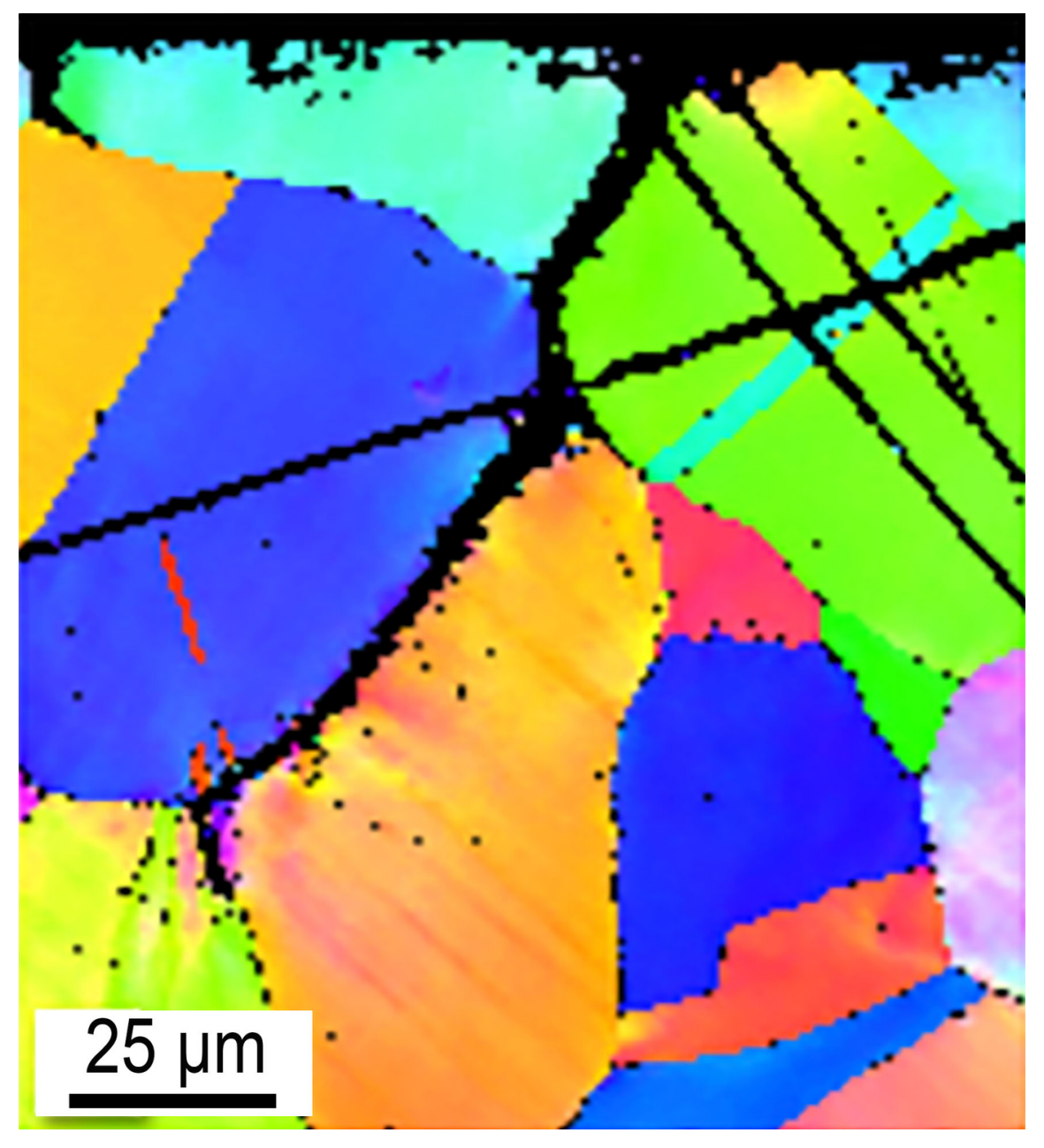




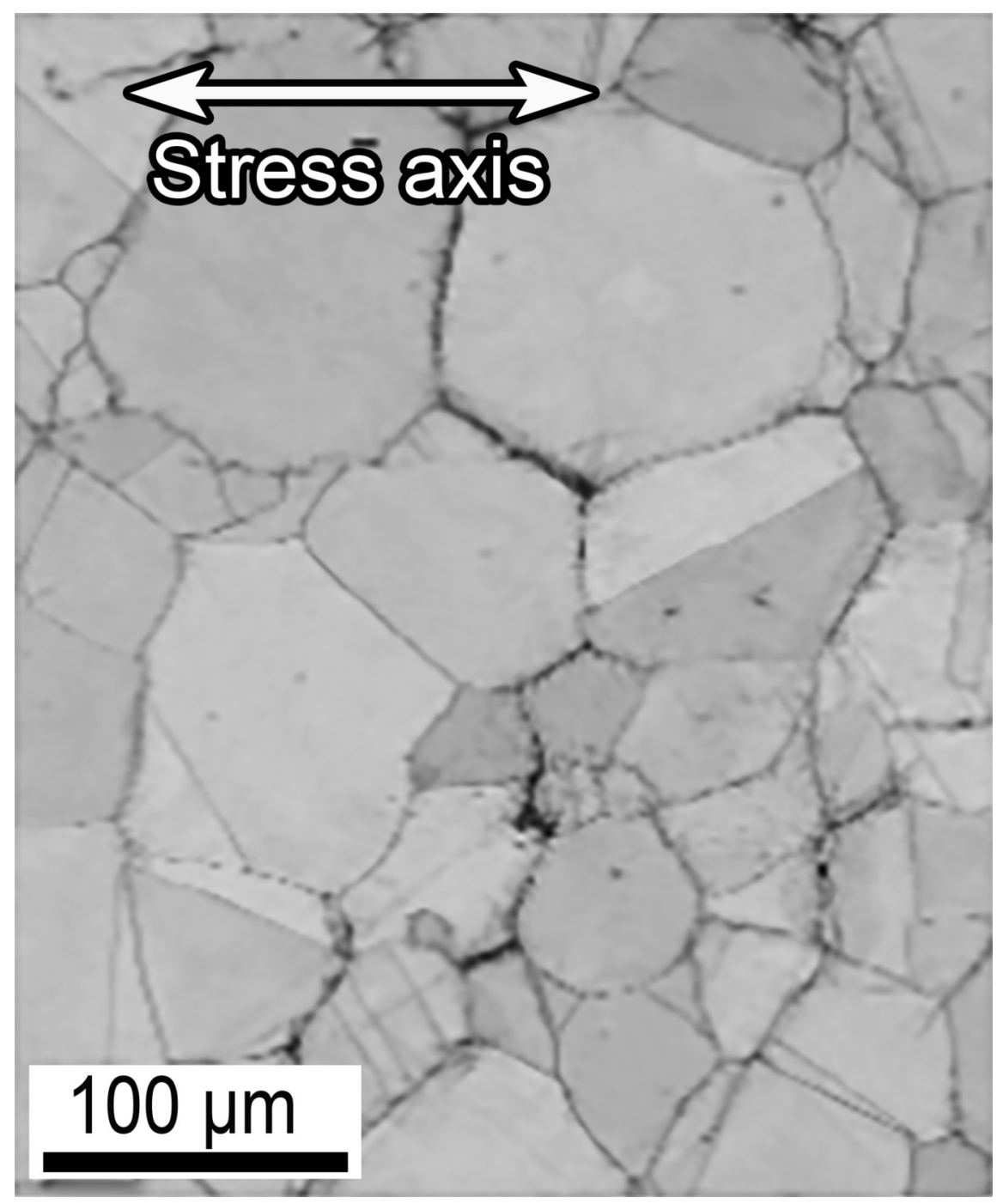




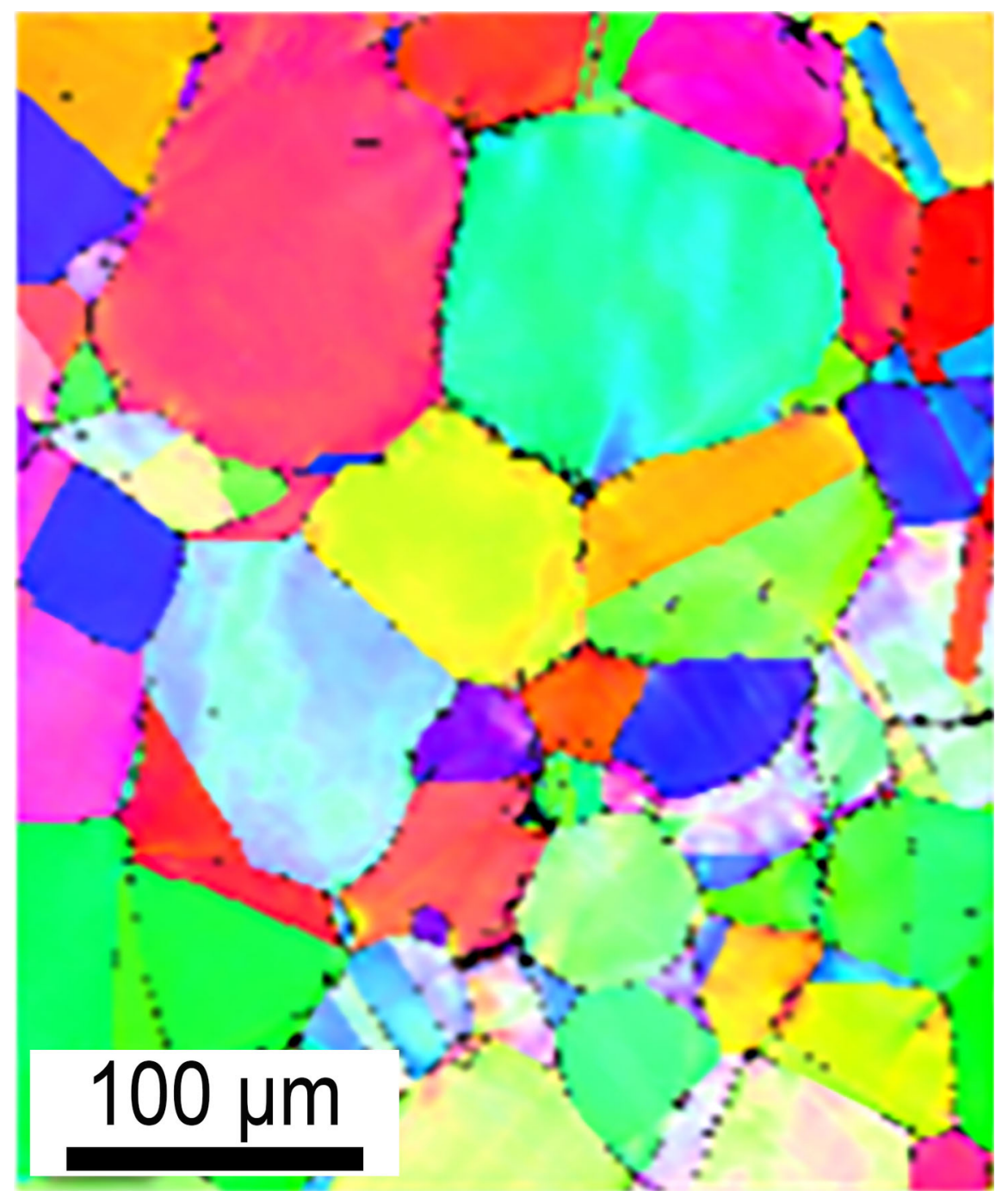



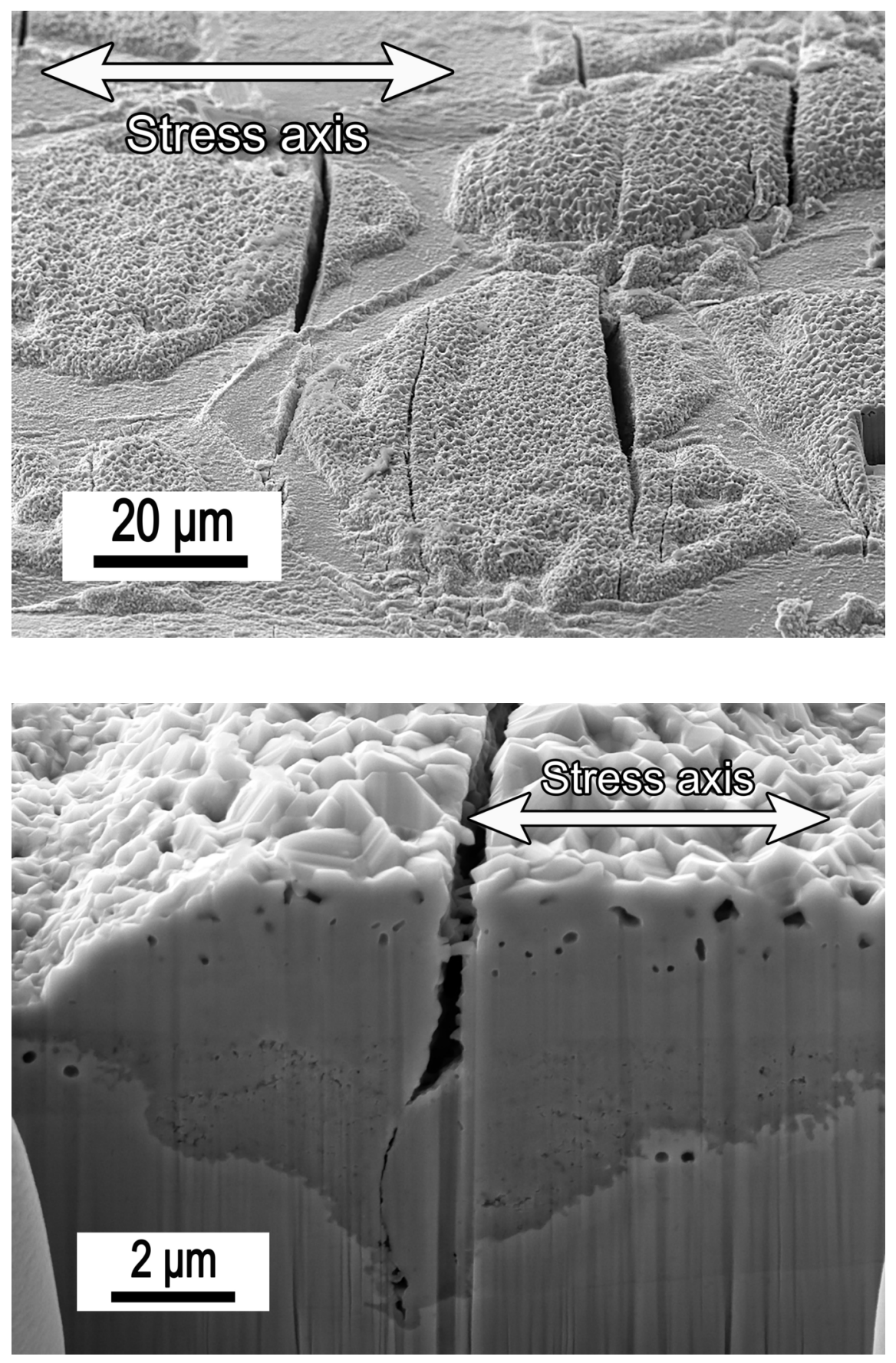

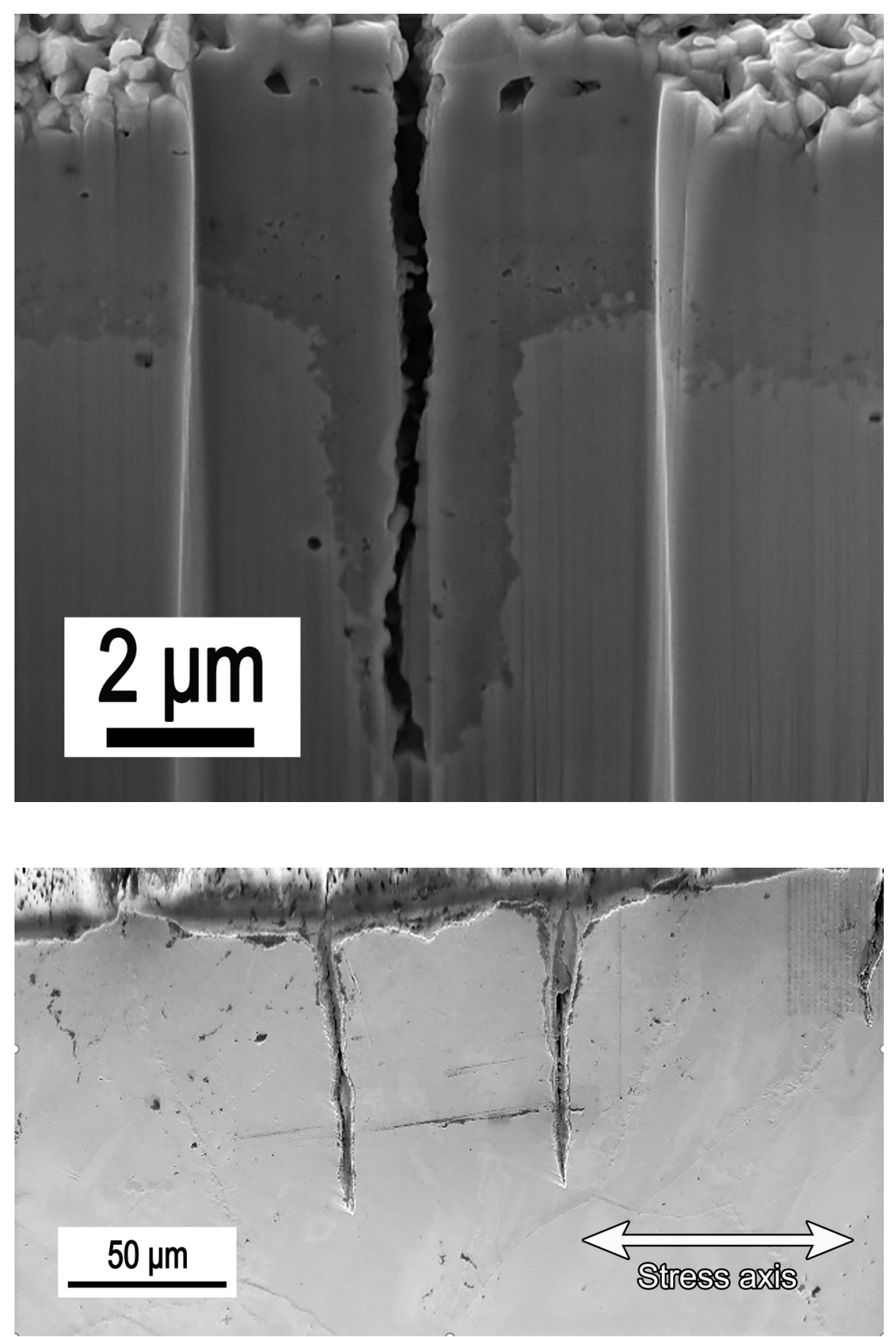

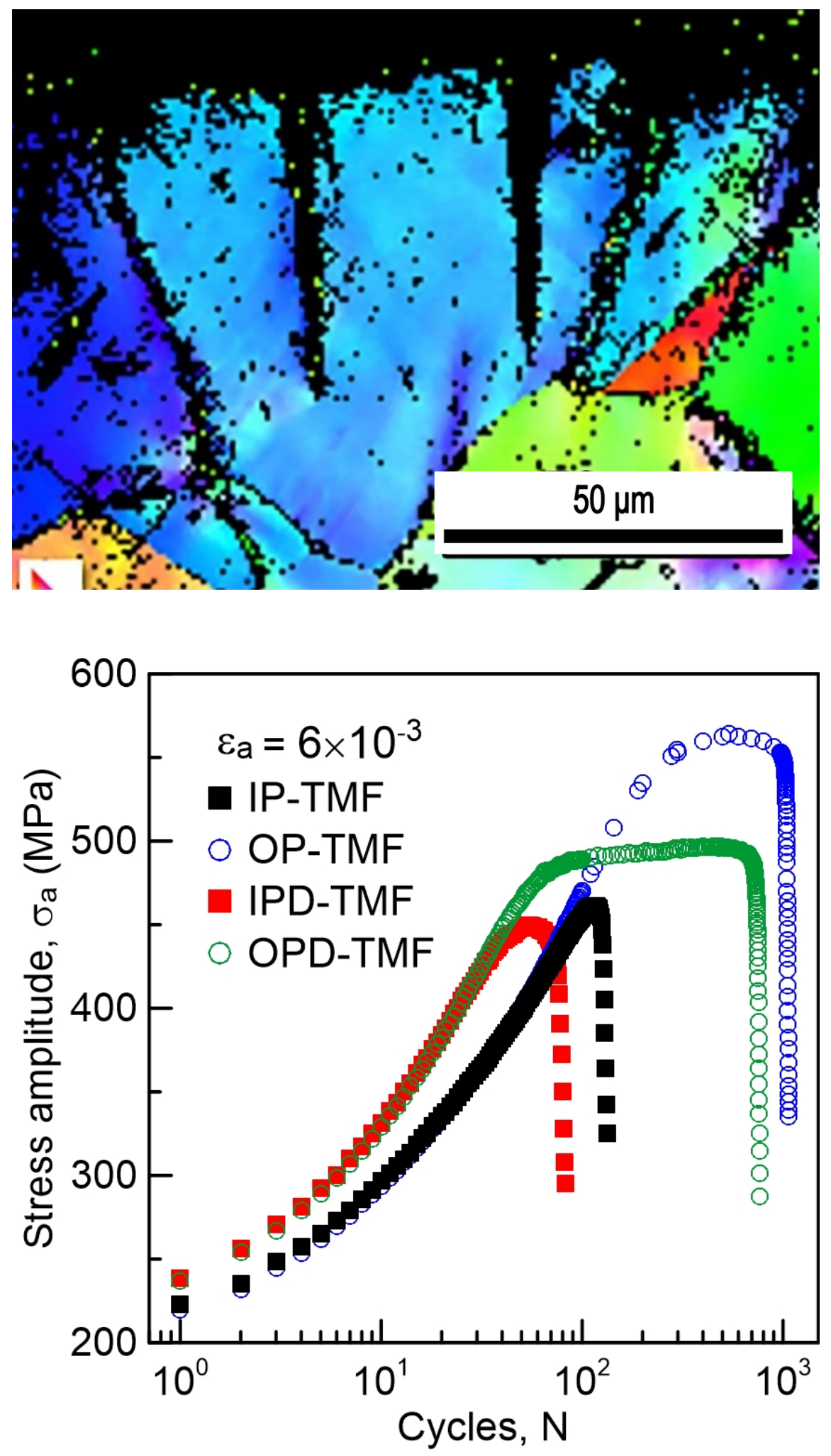


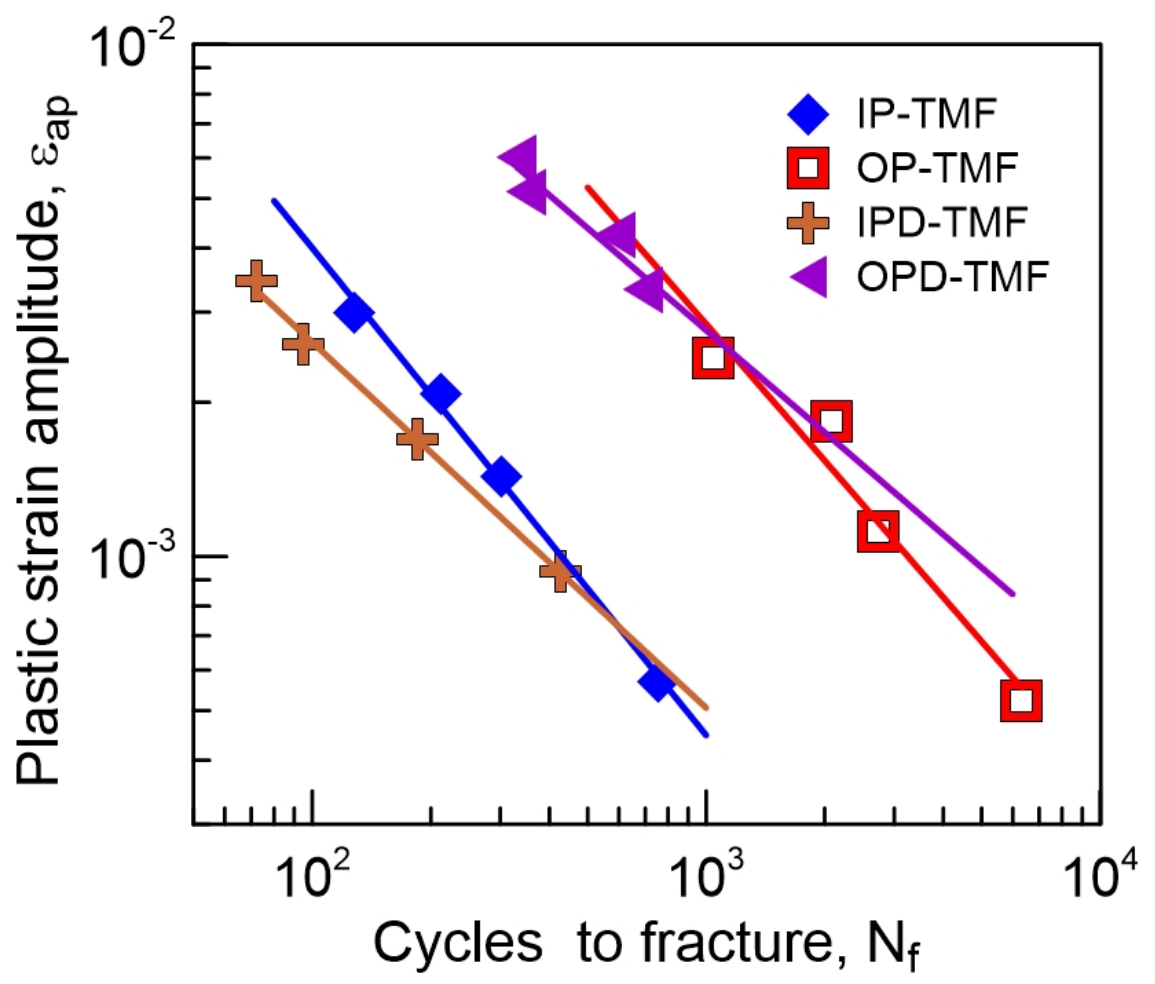

